\title{
How Many Species, Taxa, or Lineages of Cebus albifrons (Platyrrhini, Primates) Inhabit Ecuador? Insights from Mitogenomics
}

\author{
Manuel Ruiz-García, et al. [full author details at the end of the article]
}

Received: 26 February 2018 / Accepted: 30 July 2018/Published online: 03 October 2018

(C) Springer Science+Business Media, LLC, part of Springer Nature 2018

\begin{abstract}
A first step in protecting groups of similarly structured organisms is to place them into discrete taxa. Molecular genetics and phylogeny allow us to rebuild the evolutionary history of these taxa. The Neotropics has roughly 34\% of Earth's primate diversity. However, the systematics of Neotropical primates is complex and controversial. The untufted (gracile) capuchins are traditionally classified as four species: Cebus albifrons, C. capucinus, C. olivaceus, and C. kaapori. Of these, Cebus albifrons has confusing intraspecific systematics with a large number of fragmented and isolated populations throughout its geographical distribution, and up to 13 morphological subspecies. The number of taxa of this species in Ecuador, some areas of northern and eastern Colombia, and Trinidad Island is particularly debated. Primatologists have defined two taxa of C. albifrons in Ecuador: a trans-Andean population: C. a. aequatorialis (or C. aequatorialis) and a cis-Andean population: C. a. yuracus (or C. yuracus). To better understand the systematics of this species, we sequenced the mitogenomes of 136 Cebus albifrons, two Cebus olivaceus, and one Cebus kaapori. Our phylogenetic analyses revealed at least nine significantly different haplogroups of $C$. albifrons in Ecuador, four of which contained exemplars from both the trans-Andean Pacific Ecuador and the cis-Andean Ecuadorian Amazon. The splits of these Ecuadorian haplogroups, and the initial diversification within them, occurred during the Middle to Late Pliocene and the beginning of the Pleistocene. Individuals we analyzed from Vichada Department in eastern Colombia were genetically distinct from other groups of C. albifrons, agreeing with morphological studies which consider it a full subspecies (C. a. albifrons). Phylogenetic analyses showed two different gracile capuchin taxa on Trinidad Island: C. a. trininatis and C. o. brunneus. We conclude that a large portion of the gracile capuchin taxa form a unique species with a complex of populations and subspecies. The species has conserved its reproductive integrity by repeated episodes of reticulation and high levels of gene flow.
\end{abstract}

Keywords Cebus albifrons · Ecuador · Gracile capuchins · Mitogenomics · Pleistocene · Pliocene $\cdot$ Spatial structure $\cdot$ Systematics 


\section{Introduction}

Understanding the genetic structure of species is important for biodiversity conservation and for management policies (Haig 1998). Biologists do not always agree on the naming of taxa, partly because of the species concept they adopt and the data they use, including fossils, DNA results, morphology, ethology, and ecology. Molecular genetics markers (DNA) and phylogeny (Nei 1987) allow us to rebuild the evolutionary history of taxa. Mitochondrial DNA (mtDNA) is one of the most common molecular markers used to reconstruct evolutionary history. Sequencing complete mtDNA molecules (mitogenomes) is useful for phylogenetic questions because mitogenomes accumulate mutations rapidly and have a rapid coalescence time (i.e., a small number of generations to the most recent common ancestral sequence). Mitogenomes also lack introns and have a high number of copies per cell, making mitogenomic data easy to obtain and sequence, especially in low-quality samples such as hairs, teeth, or small pieces of skin. They also have a negligible recombination rate, and haploid inheritance (Avise et al. 1987; Guschanski et al. 2013; Mason et al. 2011). Although they represent a single linked locus, selection pressures and evolutionary rates are highly heterogeneous across the mtDNA (Galtier et al. 2006; Nabholz et al. 2012). For all of these reasons, mitogenomes detect differentiated linages within species and among related species more precisely than nuclear genes do (Moore 1995).

The Neotropics is the most taxonomically rich terrestrial system in the world and covers an expansive area including Mexico, the Caribbean, Central America, and South America. Within this area, we find roughly $34 \%$ of Earth's primate diversity and in some areas of the Neotropics, such as the Western Amazon, primates make up up to $40 \%$ (Mittermeier and Richardson 2013) of the mammalian biomass (save flying mammals) (Janson and Emmons 1990). The systematics of Neotropical primates is complex and controversial among primatologists, with continuous revisions of classifications in some taxonomic groups. The phenotypic similarity among howler monkey species (Alouatta) and the high variability within species of capuchins (Cebus), for instance, make systematics very challenging. We have also seen a steady increase in the number of species with the use of the Phylogenic Species Concept (Cracraft 1983, 1989) rather than the Biological Species Concept (Mayr 1963, 1970) and with the discovery of new taxa in museums and the wild (Groves 2001; Mittermeier 1982; Rylands et al. 2012).

The phylogenetic relationships among the current Neotropical Primate genera are well reconstructed with different sets of molecular markers (Schneider and Sampaio 2015). However, the systematics between species within genera and at an intraspecific level are highly controversial in many taxa. This is the case for the capuchins (Cebus Erxleben 1777, and for some authors Cebus and Sapajus Kerr 1792). Along with the howler monkeys (Alouatta Lacépede 1799), capuchins have the widest distribution of any Neotropical primate genus, from Guatemala and Belize to northern Argentina (Ruiz-García et al. 2012). Two groups of capuchin monkeys are described: the untufted (or gracile) capuchins and the tufted (or robust) capuchins. Four species are traditionally described within the untufted capuchins: Cebus albifrons, C. capucinus, C. olivaceus, and C. kaapori. Of these, the white-fronted capuchin (Cebus albifrons, Humboldt 1812) is a medium-sized monkey (body mass $2.9 \mathrm{~kg}$ for females and $3.4 \mathrm{~kg}$ for males), which has hairs on a smooth crown. The crown-cap extends forward and is rounded in front. The forehead is light. The body pelage color is a shade of brown, and 
the hands, feet, and the distal part of the tail are a lighter color (Groves 2001). Its distribution includes Bolivia, Brazil, Colombia, Ecuador, Peru, Trinidad Island, and Venezuela. It is omnivorous and lives in a variety of biomes, including gallery forests and island forests in Colombian Eastern Llanos, and closed-canopy rainforests in Ecuador or Peru (Groves 2001).

Cebus albifrons has very confusing intraspecific systematics with a large number of fragmented and isolated populations throughout its geographical distribution, especially in Colombia and Ecuador. The first systematics of $C$. albifrons was completed by Hershkovitz (1949), who defined 13 subspecies (Table I). More recently, Rylands et al. (2000) proposed 10 subspecies, Groves $(2001,2005)$ proposed 6 subspecies, and de Silva (2001) did not propose subspecies within C. albifrons (Table I).

Two mitochondrial studies have focused on the systematics of Cebus albifrons (Boubli et al. 2012; Ruiz-García et al. 2010). Neither study resolved the systematics of $C$. albifrons in Ecuador, some areas of northern and eastern Colombia, and Trinidad Island. In Ecuador, authors traditionally consider two taxa: C. a. aequatorialis in the Pacific area of the trans-Andean (western) Ecuador and C. a. yuracus (C. c. cuscinus for Groves 2001, 2005) for the cis-Andean Amazonian (eastern) Ecuador. Some authors regard these two taxa as full species (C. aequatorialis and C. yuracus; Rylands and Mittermeier 2013; Tirira 2016).

We analyzed the mtDNA of Cebus albifrons in Ecuador to contribute to our understanding of the systematics of this species. We addressed seven objectives: 1) to determine how many different mitochondrial haplogroups of $C$. albifrons are present in Ecuador; 2) to estimate the temporal splits among and within haplogroups detected in Ecuador; 3) to determine the genetic diversity in each Ecuadorian haplogroup; 4) to reconstruct the possible historical demographic trajectories of these haplogroups; 5) to determine the spatial genetic structure of $C$. albifrons in Ecuador; 6) to examine the systematics of $C$. albifrons in the Colombian Eastern Llanos and on Trinidad Island; and 7) to determine if $C$. albifrons is a full species or a complex of different species as claimed by Boubli et al. (2012).

\section{Methods}

\section{Samples}

We sequenced mitogenomes of 144 primates (139 Cebus albifrons and closely related taxa) (Table II, Fig. 1). Although some authors use the genus Sapajus for the robust capuchins (Lynch-Alfaro et al. 2012), Ruiz-García et al. (2016a) showed strong support for the use of Cebus for both kinds of capuchins. Thus, we used the genus Cebus for both gracile and robust capuchins.

We obtained DNA from hair, teeth, muscle, and blood collected from exemplars found alive or dead in Indian, colono, or mestizo communities. We asked permission to collect biological materials from either carcasses or live animals that were already present in communities. We sampled small pieces of tissue (muscle or blood) or teeth from hunted animals that were discarded during the cooking process, or hairs with bulbs plucked from live pets. We visited each community once, all sample donations were voluntary, and we offered no financial or other inducement for supplying samples 


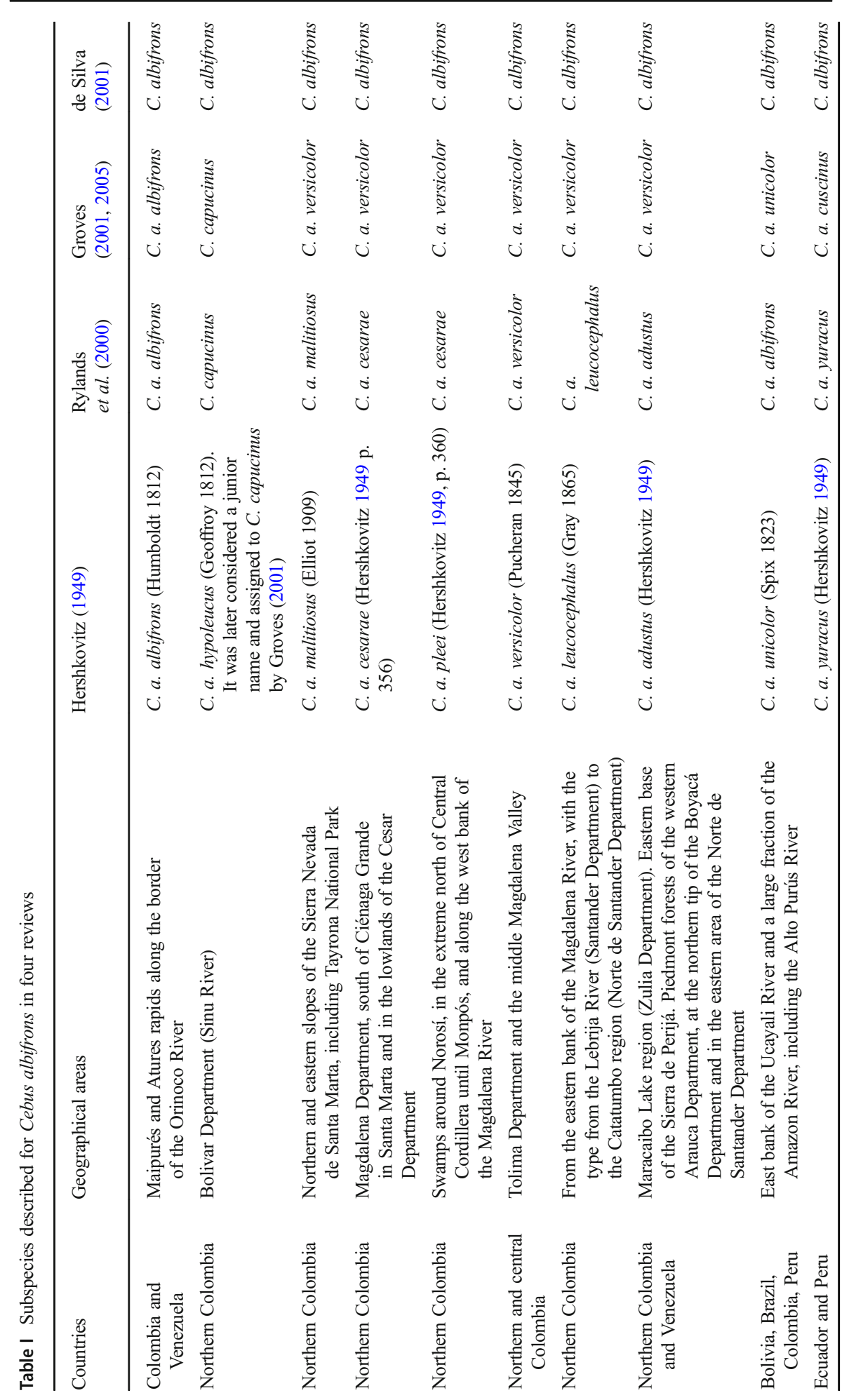




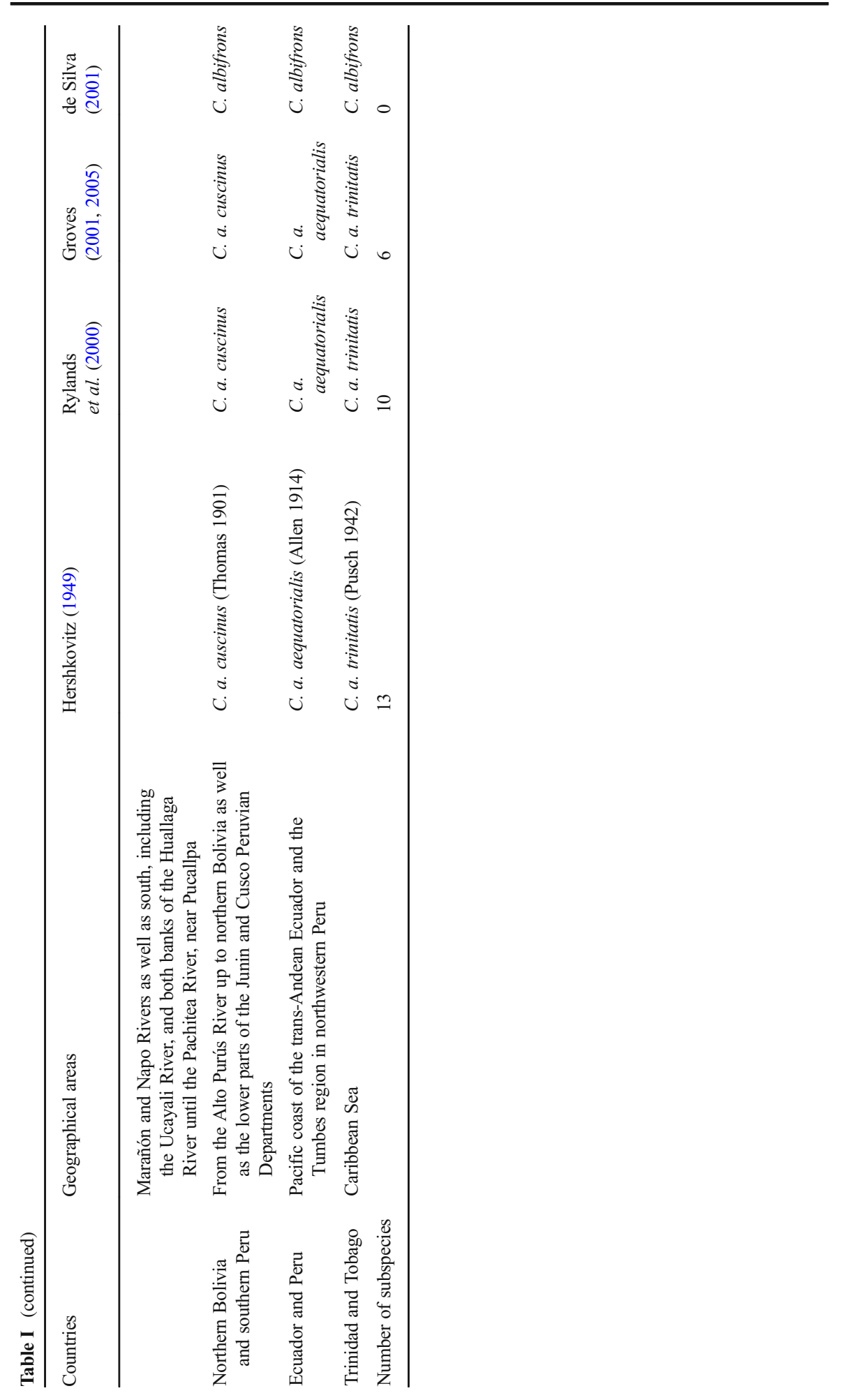


Table II Numbers and locations of Cebus albifrons and other gracile capuchin taxa sampled throughout South America for a mitogenomic study

\begin{tabular}{|c|c|c|}
\hline Taxa & No. & Sample location \\
\hline \multicolumn{3}{|l|}{ South America, excluding Ecuador } \\
\hline C. a. cesarae-pleei & 9 & Northern Atlantic Colombia \\
\hline C. a. versicolor & 21 & Magdalena River basin (Colombia) \\
\hline C. a. malitosus & 5 & Tayrona NP (Sierra Nevada de Santa Marta) (Colombia) \\
\hline C. a. malitiosus & 1 & Turbo (Antioquia Department) in northern Colombia \\
\hline C. a. adustus & 7 & $\begin{array}{l}\text { Eastern area of the Norte de Santander, Arauca, Boyacá, and } \\
\text { Meta Departments (Colombia) }\end{array}$ \\
\hline C. a. albifrons & 3 & Vichada Department (Colombia) \\
\hline Unclear subspecies status & 6 & Vaupés Department (Colombia) \\
\hline C. a. trinitatis & 1 & Trinidad Island (Trinidad and Tobago) \\
\hline C. a. unicolor (a priori) & 14 & Colombian (8), Brazilian (4), and Bolivian (2) Amazon \\
\hline C. a. yuracus (a priori) & 12 & Huallaga and middle Ucayali rivers, Peruvian Amazon \\
\hline Unclear subspecies status & 1 & San Martin Department (Peru) \\
\hline C. a. cuscinus (a priori) & 7 & Southern Peruvian Amazon (Madre de Dios River Basin, Peru) \\
\hline C. olivaceus brunneus & 1 & Trinidad Island (Trinidad and Tobago) \\
\hline C. olivaceus castaneus & $1^{\mathrm{a}}$ & Pará State (Brazil) \\
\hline C. kaapori & $1^{\mathrm{a}}$ & Maranhao State (Brazil) \\
\hline \multicolumn{3}{|l|}{ Ecuador } \\
\hline C. a. aequatorialis (a priori) & 2 & Esmeraldas-Imbabura Province (Cotacachi -Cayapas) (Ecuador) \\
\hline C. a. aequatorialis (a priori) & 4 & Pichincha Province (Ecuador) \\
\hline C. a. aequatorialis (a priori) & 3 & Manabí Province (Ecuador) \\
\hline C. a. yuracus (a priori) & 9 & Napo Province (Ecuador) \\
\hline C. a. yuracus (a priori) & 20 & Pastaza Province (Ecuador) \\
\hline C. a. yuracus (a priori) & 3 & Morona-Santiago Province (Ecuador) \\
\hline C. a. yuracus (a priori) & 4 & Loja Province (Ecuador) \\
\hline C. a. yuracus (a priori) & 4 & Zamora-Chinchipe Province (Ecuador) \\
\hline C. (Sapajus) apella & 3 & Putumayo, Guainía, Amazonas Departments (Colombia) \\
\hline Saimiri sciureus albigena & 2 & Eastern Llanos (Colombia) \\
\hline Total & 144 & \\
\hline
\end{tabular}

a Sample donated by H. Schneider and I. Sampaio

for analysis. During the sampling process (pets and hunted animals), we interviewed the indigenous hunters who said that hunted and captured animals came not from more than 10-15 km away from their respective communities. All the samples we used came from the wild with the exception of 10 samples from the mammal collection of the Instituto de Ciencias Biológicas (MEPN) de la Escuela Politécnica Nacional de QuitoEcuador.

\section{Molecular Procedures}

We extracted and isolated high-quality DNA with the QIAamp DNA Mini Kit (Qiagen, Inc.) for blood samples (DNA Purification from blood or body fluids; Spin Protocol) and 


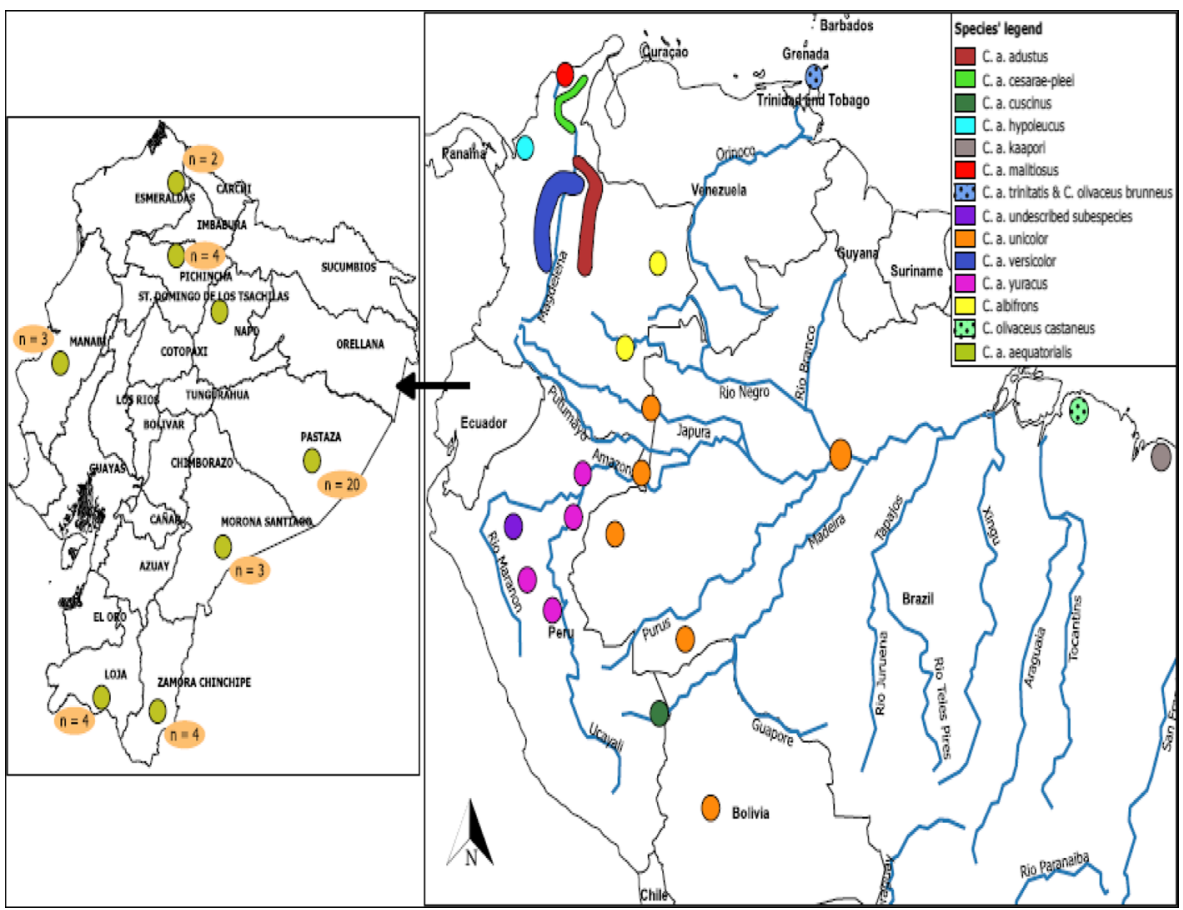

Fig. 1 Map with the geographical origins and sample sizes of Cebus albifrons exemplars for which we sequenced the mitogenome throughout South America (right) and focusing on Ecuador (left).

muscle samples (DNA Purification from tissues), and extracted DNA samples from hair and teeth with $10 \%$ Chelex resin (Walsh et al. 1991). To amplify Cebus albifrons mtDNA, we used the LongRange PCR Kit (Qiagen, Inc.) with final volume reactions of $25 \mu \mathrm{l}$. The reaction mix was composed of a 80-200 ng DNA template, 2 units of long-range polymerase chain reaction (PCR) enzyme, $3 \mu$ of $10 \times$ long-range PCR buffer, $4 \mu \mathrm{l}$ (15 pmol) of each primer, and $2 \mu \mathrm{l}$ of $10 \mathrm{mM}$ dNTPs. The cycling conditions were as follows: $95{ }^{\circ} \mathrm{C}$ for $3 \mathrm{~min}$, followed by 50 cycles denaturing at $95{ }^{\circ} \mathrm{C}$ for $20 \mathrm{~s}$, primer annealing at $53-58^{\circ} \mathrm{C}$ (depending on primer set, with a decrease of $0.1^{\circ} \mathrm{C}$ every cycle) for $30 \mathrm{~s}$, and extension at $72{ }^{\circ} \mathrm{C}$ for $10 \mathrm{~min}$. This was followed by 30 cycles of denaturing at $95{ }^{\circ} \mathrm{C}$ for $20 \mathrm{~s}$, annealing at $48-53{ }^{\circ} \mathrm{C}$ (depending on primer set) for $30 \mathrm{~s}$, and extension at $72{ }^{\circ} \mathrm{C}$ for $5 \mathrm{~min}$, with a final extension at $72{ }^{\circ} \mathrm{C}$ for $10 \mathrm{~min}$. Using four sets of primers to generate overlapping amplicons 3345-5049 base pairs (bp) long allowed us to carry out a quality test for genome circularity (Bensasson et al. 2001; Thalmann et al. 2004). We show the results of $16 \mathrm{mt}$ genes (two rRNA, D-loop and 13 protein codifying genes: $D$-loop, 610 bp; 12S rRNA, 930 bp; 16S rRNA, 1580 bp; ND1, 950 bp; ND2, 1035 bp; COI, 657 bp; COII, 720 bp; ATP8, 205 bp; ATP6, 695 bp; COIII, 775 bp; ND3, 340 bp; ND4L, 305 bp; ND4, 1380 bp; ND5, 1810 bp; ND6, 530 bp and Cyt-b, 1140 bp). We concatenated sequences using SequenceMatrix v. 1.7.6 (Vaidya et al. 2011). We used 13,662 bp for analysis, representing ca. $80-85 \%$ of the total mitochondrial DNA. We examined overlapping regions for irregularities, such as frameshift mutations and premature stop codons. The lack of such irregularities suggests the absence of nuclear mitochondrial pseudogenes (numts) in our analyses. 
We checked all amplifications in $2 \%$ agarose gels including positive and negative controls. We visualized the gels in a Hoefer UV Transilluminator. We sequenced both mt DNA strands directly using BigDye Terminator v3.1 (Applied Biosystems, Inc.). We used a 377A (ABI) automated DNA sequencer. We sequenced samples in both directions to ensure sequence accuracy.

\section{Data Analyses}

Phylogenetics procedures We used MrModeltest v2.3 (Nylander 2004) and Mega 6.05 software (Tamura et al. 2013) to determine the best evolutionary mutation model for the sequences we analyzed for each individual gene, for different partitions and for all the concatenated sequences. We used Akaike information criterion (AIC; Akaike 1974; Posada and Buckley 2004) and the Bayesian information criterion (BIC; Schwarz 1978) to determine the best evolutionary nucleotide model.

We constructed phylogenetic trees using two procedures: maximum likelihood tree and Bayesian analysis. We obtained the maximum likelihood tree using RAxML v.7.2.6 (Stamatakis 2006). To select the best fitting model, we ran 50 independent iterations using three data partitions (codon 1, codon 2, codon 3). We also ran 50 iterations using two data partitions (codons $1+2$ combined, codon 3 ). For each analysis, we used the GTR $+\mathrm{G}$ model (general time reversible model + gamma distributed rate variation among sites; Lanave et al. 1984) to search for the maximum likelihood tree and we estimated topological support with 500 bootstrap replicates (Stamatakis 2006). We performed the Bayesian analysis using a GTR $+\mathrm{G}$ model because this was the best model using MrModeltest v2.3. We completed Bayesian analysis with the BEAST v. 1.8.1 program (Drummond et al. 2012). We ran four independent iterations using three data partitions (codon 1, codon 2, codon 3) with six Markov Chain Monte Carlo chains sampled every 1000 generations for 20 million generations after a burn-in period of 2 million generations. We checked for convergence using Tracer v1.6 (Rambaut et al. 2013). We plotted the likelihood versus generation and estimated the effective sample size (ESS > 200) of all parameters across the four independent analyses. We combined the results from different runs using LogCombiner v1.8.0 (Rambaut and Drummond 2013a) and TreeAnnotator v1.8.0 (Rambaut and Drummond 2013b). We used a Yule speciation model and a relaxed molecular clock with an uncorrelated log-normal rate of distribution (Drummond et al. 2006). Posterior probability values provide an assessment of the degree of support of each node on the tree. We considered values higher than 0.95 as strong support for monophyletic clades (Erixon et al. 2003; Huelsenbeck and Rannala 2004). We visualized trees in FigTree v. 1.4 (Rambaut 2012). We used BEAST v. 1.8.1 to estimate the time to most recent common ancestor (TMRCA) for different nodes of the Bayesian analysis. We used a prior of $15.05 \pm 1$ MYA (95\% confidence interval: 10.78-16.69 MYA) for the split of the common ancestor of Cebus and Saimiri. This prior was a mean obtained from the paleontological record (18 MYA, MacFadden 1990; 12.1 MYA, Neosimiri, Takai 1994).

To estimate possible divergence times among the mitochondrial haplotypes we found in the Ecuadorian Cebus albifrons and to compare them with Bayesian estimations, we constructed a median joining network (Bandelt et al. 1999) using Network 4.6.0.1 (Fluxus Technology Ltd). We estimated the $\rho$ statistic (Morral et al. 1994) and its standard deviation (Saillard et al. 2000) and transformed them into years. The $\rho$ statistic is unbiased and independent of past demographic events. This approach is named "borrowed molecular 
clocks" and uses direct nucleotide substitution rates inferred from other taxa (Pennington and Dick 2010). We employed an evolutionary rate of $0.92 \%$ per one MY, which represented one mutation each 682 years for the 13,662 bp analyzed (Ashley and Vaughn 1995; Ruiz-García and Pinedo-Castro 2010; Ruiz-García et al. 2014). An advantage of the median joining network procedures compared to traditional trees is that they explicitly allow for the coexistence of ancestral and descendant haplotypes, whereas traditional trees treat all sequences as terminal taxa (Posada and Crandall 2001). Using the median joining network allows us to observe which current taxa began to evolve first and also to identify the more recently derived taxa.

Genetic Distances and Genetic Heterogeneity We used the Kimura 2P genetic distance (Kimura 1980) to determine the percentage genetic difference among the different Ecuadorian haplogroups of Cebus albifrons and between them and other C. albifrons taxa, C. olivaceus, C. kaapori, C. apella, and S. sciureus. We considered large clusters with significant bootstraps higher than 60\% lax limit (Hillis and Bull 1993) as different haplogroups. The Kimura $2 \mathrm{P}$ genetic distance is a standard measurement for barcoding tasks (Hebert et al. 2003, 2004). Sequences of mtCOI from 20,731 vertebrate and invertebrate animal species have values of $0.89 \% \pm 0.16 \%$ for populations within species, $3.78 \% \pm 1.18 \%$ for subspecies or semispecies, and $11.06 \% \pm 0.53 \%$ for species within a genus (Kartavtsev 2011). mtCOII has a mean genetic distance of $6 \%$ among species within a genus, and 2-4\% for subspecies (Ascunce et al. 2003; Collins and Dubach 2000; Ruiz-García et al. 2014). For $\mathrm{mtC} y t b$, values $<2 \%$ equal intraspecific variation, values between 2 and $11 \%$ merit additional study, and values $>11 \%$ indicate species (Bradley and Baker 2001). For mtD-loop, values of 5-7\% of differences indicate different species and ca. 2\% indicate subspecies in mammals (Avise 1994). We used the means of these values in our study: $4 \%$ as possible subspecies, $9 \%$ as different species of the same genus. For different genera, the mean value should be $16 \%$ or higher (Kartavtsev 2011).

We calculated $H_{\mathrm{ST}}, K_{\mathrm{ST}}, K_{\mathrm{ST} *}, \gamma_{\mathrm{ST}}, N_{\mathrm{ST}}$, and $F_{\mathrm{ST}}$ for the nucleotide sequences to determine the overall genetic heterogeneity among the different Ecuadorian haplogroups of Cebus albifrons (Hudson et al. 1992). We obtained indirect gene flow estimates assuming an infinite island model (Wright 1965). We estimated significance was using permutation tests with 10,000 replicates. We calculated heterogeneity statistics with the DNAsp 5.1 (Librado and Rozas 2009) and Arlequin 3.5.1.2 programs (Excoffier and Lischer 2010).

Genetic Diversity Statistics for the Ecuadorian Cebus albifrons Haplogroups We used the following statistics to determine the genetic diversity of the different Ecuadorian haplogroups of $C$. albifrons: number of haplotypes $(H)$, haplotype diversity $\left(H_{\mathrm{d}}\right)$, nucleotide diversity $(\pi)$, and $\theta$ statistic by sequence. We calculated these genetic diversity statistics with the DNAsp 5.1 (Librado and Rozas 2009).

Demographic Evolutionary Changes We used two procedures to determine possible historical female population changes in the different Ecuadorian Cebus albifrons's haplogroups. First, we obtained the mismatch distribution (pairwise sequence differences) following the method of Rogers and Harpending (1992) and Rogers et al. (1996). We used the raggedness $r g$ statistic (Harpending 1994; Harpending et al. 
1993) to determine the similarity between the observed and the theoretical curves. Second, we used $\mathrm{Fu}$ and $\mathrm{Li} D^{*}$ and $F^{*}$ tests (Fu and $\left.\mathrm{Li} 1993\right)$, the $\mathrm{Fu} F_{\mathrm{S}}$ statistic (Fu 1997), the Tajima $D$ test (Tajima 1989), and the $R_{2}$ statistic (Ramos-Onsins and Rozas 2002) to determine possible demographic changes. We obtained a $95 \%$ confidence interval and probabilities with 10,000 coalescence permutations.

Spatial Genetic Statistics We used SAMOVA 1.0 (Dupanloup et al. 2002) to investigate population subdivision using analysis of molecular variance in a geographical context for all the Cebus albifrons sampled in Ecuador (SAMOVA, spatial analysis of molecular variance). SAMOVA 1.0 defines groups of populations that are geographically homogeneous and maximally differentiated from each other and identifies genetic barriers between these population groups. The method is based on a simulated annealing procedure that aims to maximize the proportion of total genetic variance due to differences between groups of populations. We set $k$ (number of different populations) to $2-10$ and estimated statistical significance using 1000 permutations.

We used a Mantel test (Mantel 1967) to test for a relationship between the Kimura 2P genetic distance and the geographic distance between Ecuadorian Cebus albifrons individuals. We normalized Mantel's statistic according to Smouse et al. (1986) to yield a correlation coefficient.

We used the Ay statistic (Miller 2005) for each distance class calculated in the spatial autocorrelation analysis. Ay can be interpreted as the average genetic distance between pairs of individuals that fall within a specified distance class. Ay takes a value of 0 when all individuals within a distance class are genetically identical and a value of 1 when all individuals within a distance class are completely dissimilar. The probability of each distance class is obtained using 10,000 randomizations. For the mitogenomics analysis, we defined 10 distance classes of equal size $(0-60 \mathrm{~km}$; 60-121 km; 121-181 km; 181$242 \mathrm{~km} ; 242-302 \mathrm{~km} ; 302-362 \mathrm{~km} ; 362-423 \mathrm{~km}, 423-483 \mathrm{~km}, 483-544 \mathrm{~km} ; 544$ $605 \mathrm{~km}$ ) (Ruiz-García 1993, 1994, 1997, 2000). We used AIS for this analysis (Miller 2005).

We also used Monmonier's algorithm for further spatial analysis (Monmonier 1973) with AIS (Miller 2005). This geographical regionalization procedure detects the locations of putative barriers to gene flow by iteratively identifying sets of contiguous, large genetic distances along connectivity networks (Dupanloup et al. 2002; Manel et al. 2003; Manni et al. 2004). We used a Delaunay triangulation (Brouns et al. 2003; Watson 1992) to generate the connectivity network among sampling points. This procedure superimposes a graphical representation of putative "barriers" inferred by the algorithm over the connectivity network to identify important geographical features that reflect the genetic data set. With this procedure, we detected six main geographical barriers in the mitogenomics data. Finally, we used a genetic landscape interpolation analysis using the "inverse distance weighted" procedure in AIS (Miller 2005) to view in the possible spatial genetic structure of the data analyzed in a three-dimensional perspective. We calculated the surface based on midpoints of edges derived from Delaunay triangulation, and calculated the surface heights based on residual genetic distances.

Data Availability The datasets analyzed during the current study are available from the corresponding author on reasonable request. 


\section{Ethical Note}

The sampling procedures complied with all the protocols approved by the Ethical Committee of the Pontificia Universidad Javeriana (No. 45677) and those of the Secretaria Distrital del Ambiente (No. 20161322). For more information, see the Acknowledgments. The authors have no conflict of interests.

\section{Results}

The mitogenomics data showed that the best nucleotide substitution model based on BIC and AIC was GTR + G (BIC: 285,345.344, AIC: 276,457.111).

\section{Phylogenetic Analyses}

The maximum-likelihood tree showed at least nine differentiated haplogroups of Cebus albifrons in Ecuador. These haplogroups were mixed in multiple areas with no monophyletic differentiation related to the Andean mountains (Figs. 2 and 3).

The first haplogroup (H1; bootstrap: 100\%) that included Ecuadorian Cebus albifrons contained 10 exemplars. Five of these were Ecuadorian: two from Pastaza province (central Ecuadorian Amazon), one from Zamora-Chinchipe province (southern Ecuadorian Amazon), and two from the trans-Andean Ecuadorian area (Imbabura and Guayas provinces). It also included three exemplars of $C$. apella from the Colombian Amazon.

The second haplogroup (H2, bootstrap 62\%) comprised a single Ecuadorian exemplar from Pichincha province.

The third haplogroup (H3, bootstrap: 66\%) included two Cebus albifrons, one from the Pastaza province and the other from a very distant area in northern Colombia $(C . a$. malitiosus).

The fourth haplogroup (H4, bootstrap: 90\%) included 18 Cebus albifrons. A subcluster within this haplogroup comprised exemplars from the middle Ucayali River (area of Pucallpa) and Pachitea River in Peru. H4 also included exemplars from more northern areas of the Ucayali River (area of Genaro Herrera and Requena) and the Huallaga River (area of Yurimaguas) in Peru, the Amazon River in the Colombia Amazon (near to Leticia), and the Yavari River in the western Brazilian Amazon. Seven exemplars in $\mathrm{H} 4$ were from different areas of the Ecuadorian Amazon: one from the Napo province (northern Ecuadorian Amazon), one from the Tungurahua province (Central Ecuadorian Andes), four from the Pastaza province, and one from the Zamora-Chinchipe province. Thus, $\mathrm{H} 4$ encompassed the entire cis-Andean area of Ecuador.

The fifth haplogroup (H5, bootstrap 90\%) included 12 exemplars, 10 from Ecuador and two from Peru (one from the Huallaga River and other from the middle Ucayali River). The Ecuadorian exemplars were from in Napo province (three from Puerto Misahualli and near Coca), Pastaza province (six) and Loja province (one; southern Ecuador). As for H4, H5 included the cis-Andean area of Ecuador.

The sixth haplogroup (H6, bootstrap 92\%) was a small cluster with a very high bootstrap value. It comprised three Ecuadorian exemplars, one from the trans-Andean area (Imbabura province) and two from the Morona-Santiago province (central Ecuadorian Amazon). 
The seventh haplogroup (H7, bootstrap 51\%) consisted of eight Ecuadorian exemplars. Five of these were sampled in Napo province (including one from Pantoja at the frontier between Ecuador and Peru), two from Tungurahua province, and one from Pastaza province. Thus, H7 included the central and northern Ecuadorian Amazon.

The eighth haplogroup (H8) was highly significant (bootstrap: 97\%) and is split into two significant sub-haplogroups, one from the southern Ecuadorian Amazon (Loja and ZamoraChinchipe provinces; 99\%) and the other including the majority of the trans-Andean exemplars (a priori Cebus albifrons aequatorialis) from Manabí (three) and Pichincha provinces (three), and three exemplars from the cis-Andean Amazon area in Pastaza and Loja provinces (bootstrap: 100\%).

The ninth haplogroup (H9; bootstrap: 70\%) had 11 exemplars from a large part of the western and central Amazon. Two exemplars were from Bolivia (Beni department), three from southern Peru (Madre de Dios River basin), two from the area of the Negro River (Brazil), and two from the Colombian Amazon department (near to Leticia). The two Ecuadorian exemplars were from the Morona-Santiago province (central Ecuadorian Amazon).

The Bayesian analysis showed the same haplogroups for Ecuadorian exemplars, with minor differences (Fig. 3). H2 and H3 were included in $\mathrm{H} 1(P=0.63)$, and H6 $(P=0.9)$ in $\mathrm{H} 7(P=0.75)$. The other haplogroups were the same as those observed with the maximum-likelihood tree (H4 $[P=0.97]$, H5 $[P=1]$, H8 $[P=1]$, and H9 $[P=1])$.

\section{Genetic Distances}

All the Cebus haplogroups showed genetic distances of 18-22\% from Saimiri (Table III). $\mathrm{H} 1$ (including in this case $\mathrm{H} 3$ ) showed the lowest genetic distance from $C$. kaapori and $\mathrm{H} 2$, whereas the highest genetic distances were with C. a. malitiosus and the Colombian Vichada C. albifrons haplogroup. Values for the remaining Ecuadorian haplogroups were high (6\%). $\mathrm{H} 2$ was more differentiated from other taxa than $\mathrm{H} 1$ was. The most differentiated taxa were C. kaapori and the Vichada haplogroup. Values for the remaining Ecuadorian haplogroups were high (7\%). Thus, the genetic differentiation of $\mathrm{H} 1$ and $\mathrm{H} 2$ from the other Ecuadorian haplogroups was high. For H4 (excluding the previous comparisons with H1 and H2), the highest genetic distances were from C. kaapori and the Vichada haplogroup. Values for H5, $\mathrm{H} 6, \mathrm{H} 7, \mathrm{H} 8$, and $\mathrm{H} 9$ yielded similarly high genetic distances from $C$. kaapori and the Vichada haplogroup. In addition, the distances to the other Ecuadorian haplogroups were similar to those for H4. Many of these genetic distance values are at subspecies level, and some are at species level. Nevertheless, the majority of these Ecuadorian haplogroups have undifferentiated morphotypes, live in geographical sympatry, and there is no sexual isolation among the individuals of these haplogroups (Ruiz-García unpubl. obs.), making it impossible to apply Linnaean nomenclature.

\section{Genetic Heterogeneity Statistics}

All of the genetic heterogeneity statistics were significant across the nine haplogroups of Ecuadorian $C$. albifrons (Table IV). $F_{\mathrm{ST}}(=0.527)$ and $\gamma_{\mathrm{ST}}(=0.564)$ were highly

Fig. 2 Maximum-likelihood tree based on mitogenomics of 136 Cebus albifrons, 2 C. olivaceus, 1 C. kaapori,

3 Cebus (Sapajus) apella, and 2 Saimiri albigena. Haplogroups detected in Ecuador are marked H1-H9.

Nodes are labeled with bootstrap percentages. 


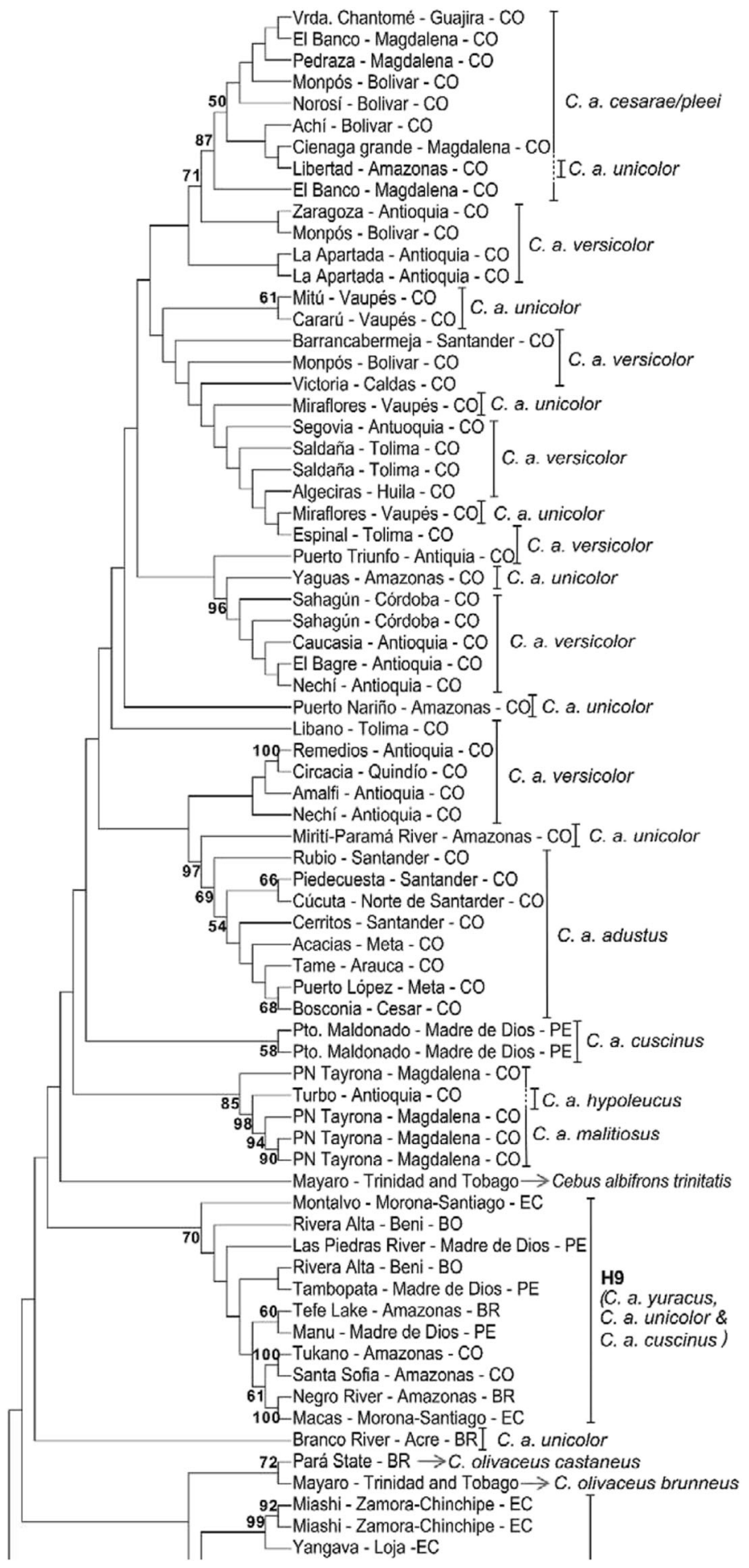




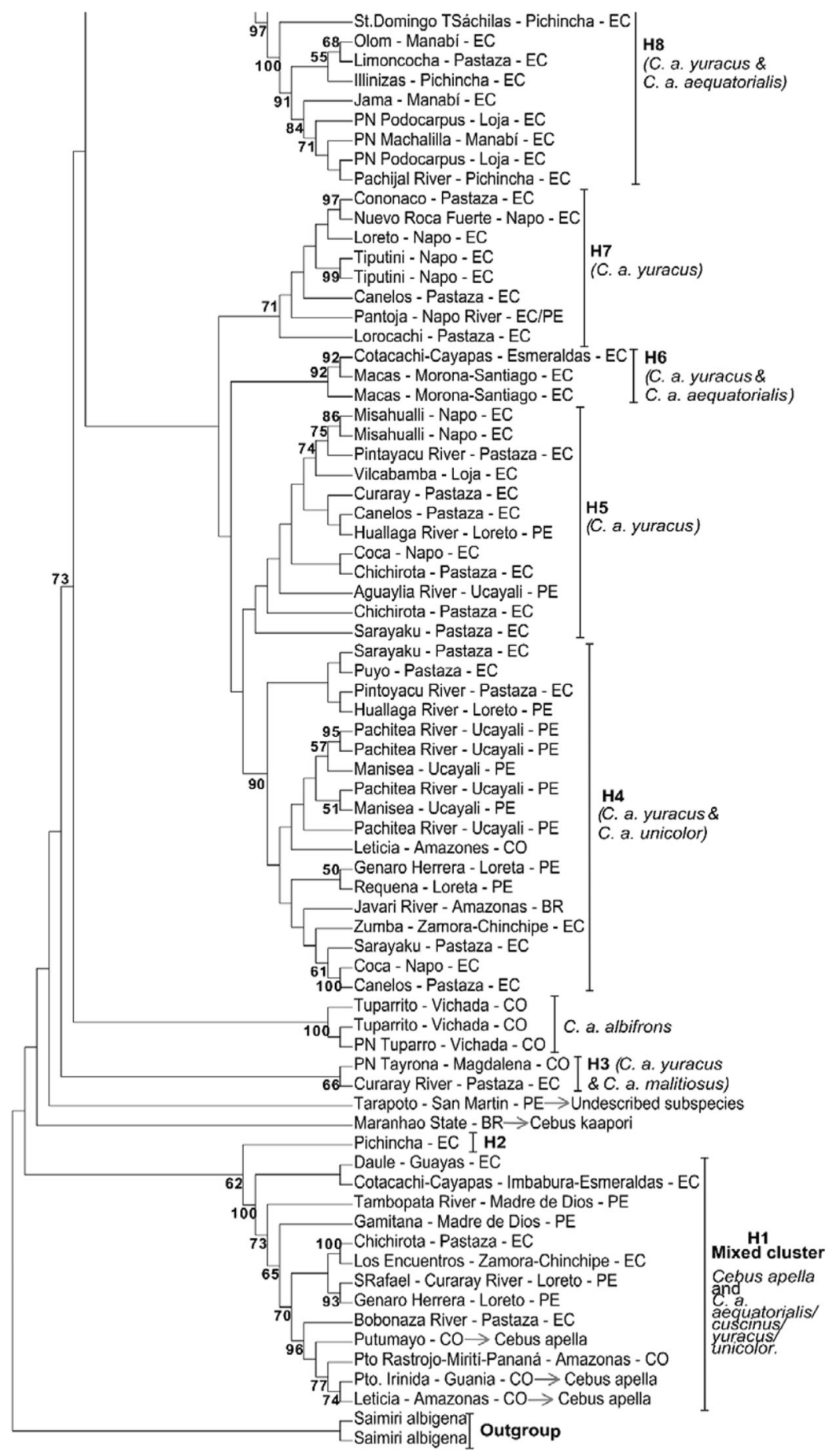

Fig. 2 (continued). 


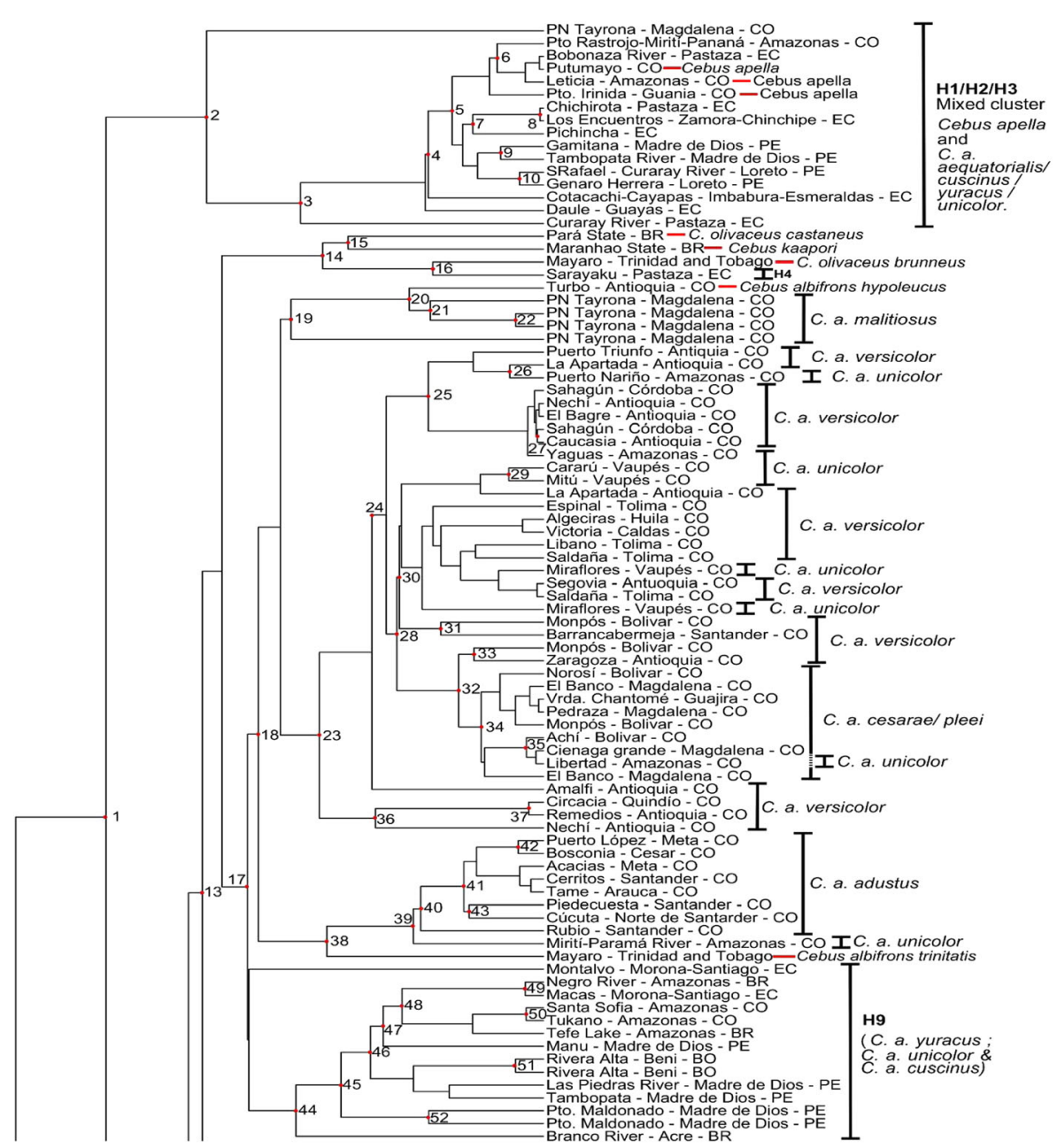

Fig. 3 Bayesian inference tree for the mitogenomics of 136 Cebus albifrons, 2 C. olivaceus, 1 C. kaapori, 3 Cebus (Sapajus) apella, and 2 Saimiri albigena (as outgroup). Haplogroups detected in Ecuador are marked $\mathrm{H} 1-\mathrm{H} 9$. Nodes with numbers correspond to those with posterior probabilities $>0.5$. The posterior probabilities, temporal splits in millions of years ago and the temporal split interval for the 95\% HPD of the numbered nodes are in Table V.

significant, indicating weak mitochondrial (= female) genetic flow among the nine haplogroups found.

\section{Temporal Splits Among the Ecuadorian Haplogroups of Cebus albifrons}

The mitochondrial diversification processes in Cebus albifrons began in the Late Miocene and continued during the Pliocene and the Pleistocene (Table V).

The temporal separation between the common ancestor of Cebus and Saimiri was estimated to occur about 14.82 MYA (node 0 in Table V). The next important temporal split was between H1 (C. apella + and some haplotypes of C. albifrons) and all the remaining haplogroups of $C$. albifrons, estimated to occur around 5.59 


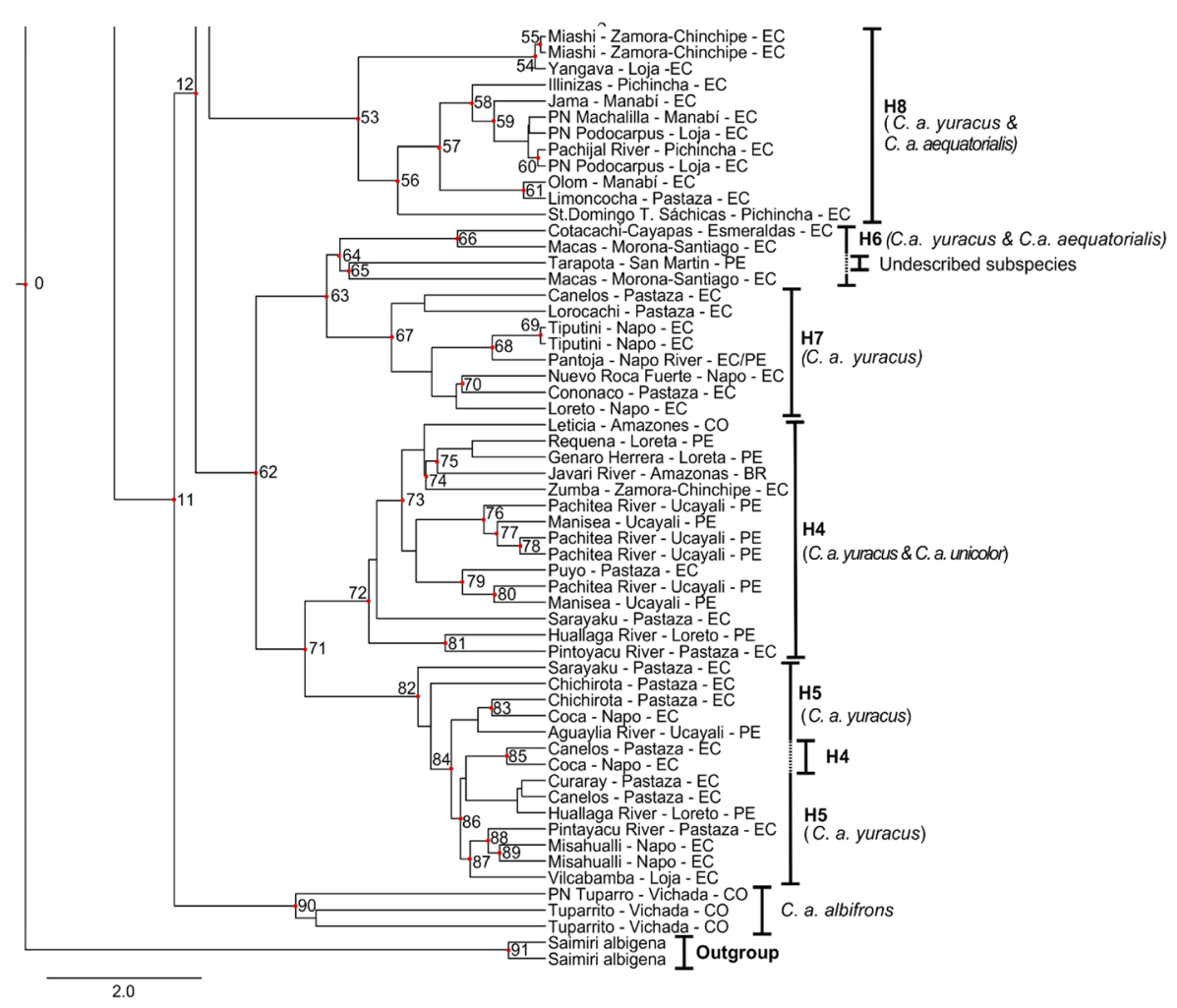

Fig. 3 (continued).

MYA (node 1). In the Bayesian analysis, H1 included $\mathrm{H} 2$ and $\mathrm{H} 3$. Within this cluster, the initial divergence corresponded to the ancestor of one C. a. malitiosus from Tayrona National Park in the northern Caribbean of Colombia, 4.31 MYA (node 2). The next to diverge was the ancestor of a $C$. albifrons from Ecuadorian Amazon at 3.1 MYA (node 3). The temporal split in the subcluster, which included closely related haplotypes of $C$. albifrons and $C$. apella, was estimated to have occurred 0.69 MYA (node 6). Thus, within H1 (including H2 and H3), the oldest divergence times were exclusively among exemplars of $C$. albifrons. The C. apella in this haplogroup split more recently. The initial temporal splits of the other haplogroups detected in Ecuador are as follows: H4 (2.29 MYA; node 72), H5 (1.65 MYA; node 82), H6 (2.66 MYA; node 64), and H7 (1.99 MYA; node 67). H8 diverged 2.43 MYA (node 53). Its two differentiable subclades diverged at 0.13 MYA (node 54), and 1.91 MYA (node 56). H9 diverged 3.76 MYA with the ancestor of one individual from the Morona-Santiago province being considerably older than the others. The remaining ancestors began to diverge around 3.16 MYA (node 44).

The median joining network analysis estimated the split between the ancestors of Cebus and Saimiri at $13.08 \pm 0.06$ MYA (Fig. 4), similar to the Bayesian estimate. The split between $\mathrm{H} 1$ (including $\mathrm{H} 2$ and $\mathrm{H} 3$ ) and other Ecuadorian 


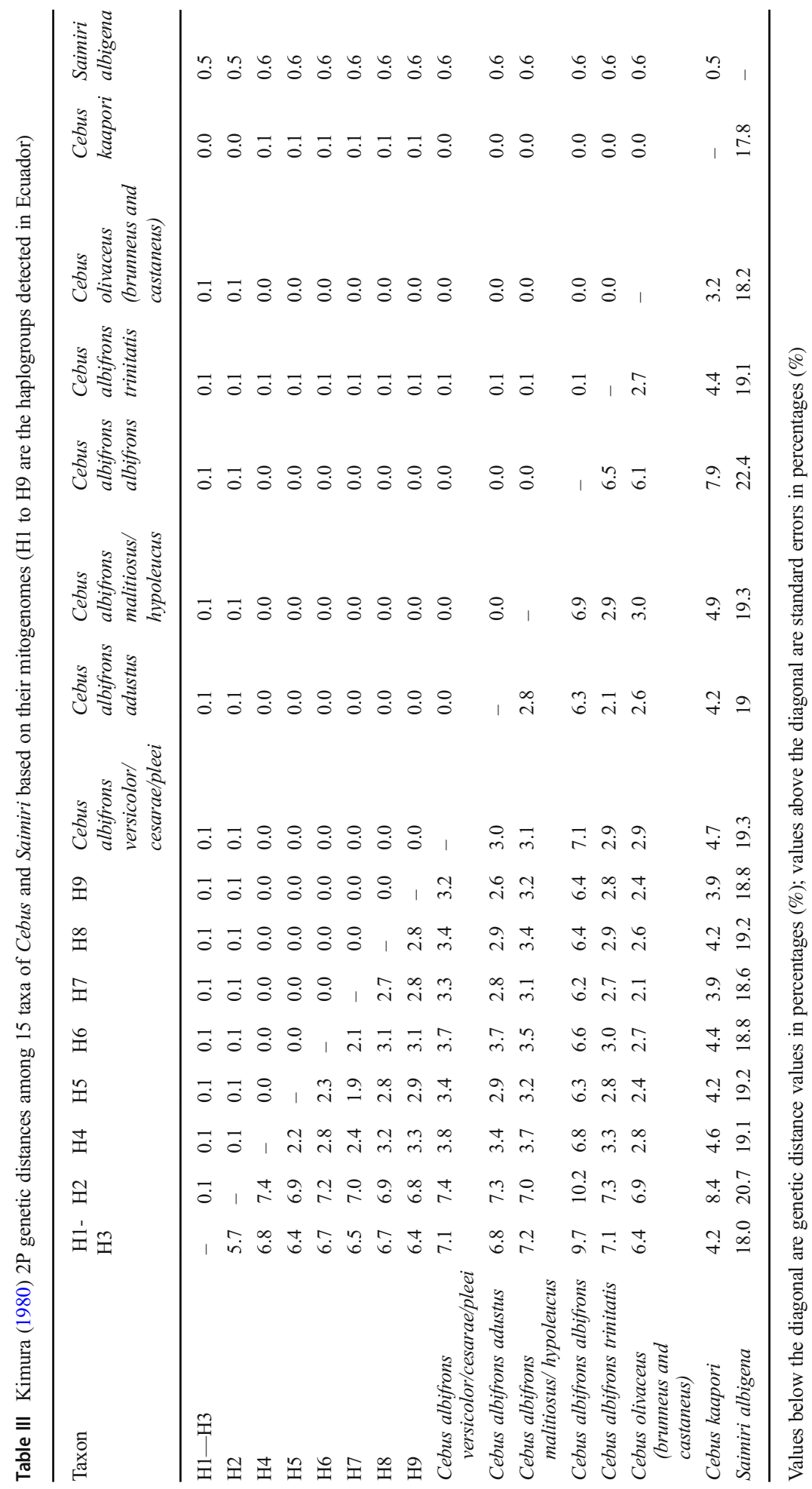


Table IV Genetic heterogeneity and gene flow statistics across nine haplogroups of Ecuadorian Cebus albifrons

\begin{tabular}{lll}
\hline Genetic heterogeneity and gene flow statistics & Values & Probability \\
\hline$\chi^{2}$ & $476.000(\mathrm{df}=438)$ & $0.0406^{*}$ \\
$H_{\mathrm{ST}}$ & 0.0054 & $0.0012^{* *}$ \\
$K_{\mathrm{ST}}$ & 0.5207 & $0.0001^{* *}$ \\
$K_{\mathrm{ST}} *$ & 0.2182 & $0.0001^{* *}$ \\
$Z_{\mathrm{S}}$ & 561.445 & $0.0001^{* *}$ \\
$Z_{\mathrm{S}} *$ & 5.6128 & $0.0001^{* *}$ \\
$S_{\mathrm{nn}}$ & 0.9031 & $0.0001^{* *}$ \\
$\gamma_{\mathrm{ST}}$ & 0.5641 & $0.0001^{* *}$ \\
$N_{\mathrm{ST}}$ & 0.5313 & $0.0001^{* *}$ \\
$F_{\mathrm{ST}}$ & 0.5257 & $0.0001^{* *}$ \\
Gene flow estimated from $\gamma_{\mathrm{ST}}$ & 0.39 & \\
Gene flow estimated from $N_{\mathrm{ST}}$ & 0.44 & \\
Gene flow estimated from $F_{\mathrm{ST} .}$ & 0.45 & \\
\hline
\end{tabular}

$d f$ degree of freedom

$* P<0.05 ; * * P<0.01$

haplogroups ranged from $4.14 \pm 0.22$ MYA $(\mathrm{H} 4$ and $\mathrm{H} 7)$ to $3.22 \pm 0.08$ MYA (H9). The diversification within $\mathrm{H} 1$ is estimated to have occurred around $1.32 \pm$ 0.12 MYA. The other diversification within the other haplogroups detected in Ecuador are as follows: H4 (2.09 +0.07 MYA), H5 $(0.75+0.09$ MYA $)$, H6 $(1.09 \pm 0.18 \mathrm{MYA}), \mathrm{H} 7(0.63 \pm 0 . \overline{1} 1 \mathrm{MYA}), \mathrm{H} 8(1.50 \pm 0 . \overline{0} 9 \mathrm{MYA})$, and H9 (1.00 \pm 0.16 MYA). The diversification estimates (2.09-0.63 MYA) obtained with median joining network are slightly lower than those obtained in the Bayesian analysis (3.16-1.65 MYA), although many of these estimates overlap. In both cases, the mitochondrial diversification within the Ecuadorian haplotypes of C. albifrons began in the Late Miocene and Upper Pleistocene.

\section{Genetic Diversity and Possible Historical Demographic Changes in the Haplogroups of Ecuadorian Cebus albifrons}

The seven haplogroups that included more than two exemplars showed extremely elevated levels of haplotype diversity (Table VI). Five haplogroups yielded a value of 1 , indicating that all exemplars in the haplogroup had different mitochondrial DNAs. The levels of nucleotide diversity were also elevated in all the haplogroups. H6 and H4 showed the highest values and $\mathrm{H} 7$ and $\mathrm{H} 8$ the lowest. These results agree quite well with the fact that all of these haplogroups are estimated to be old and large.

The demographic trajectories of the Ecuadorian haplogroups differed. H1 showed a significant mismatch distribution, supporting a population expansion (Table VI). H4 had greater evidence of a population expansion with six significant tests. However, the mismatch distribution was not significant. H5, H8, and H9 showed some significant 


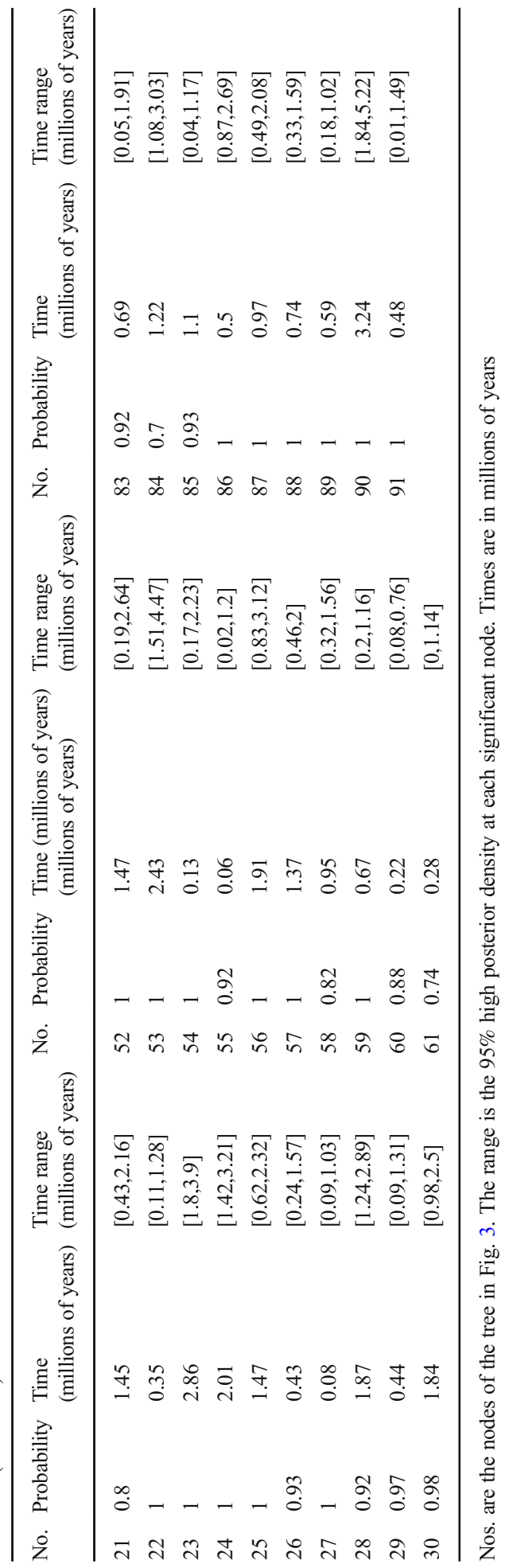




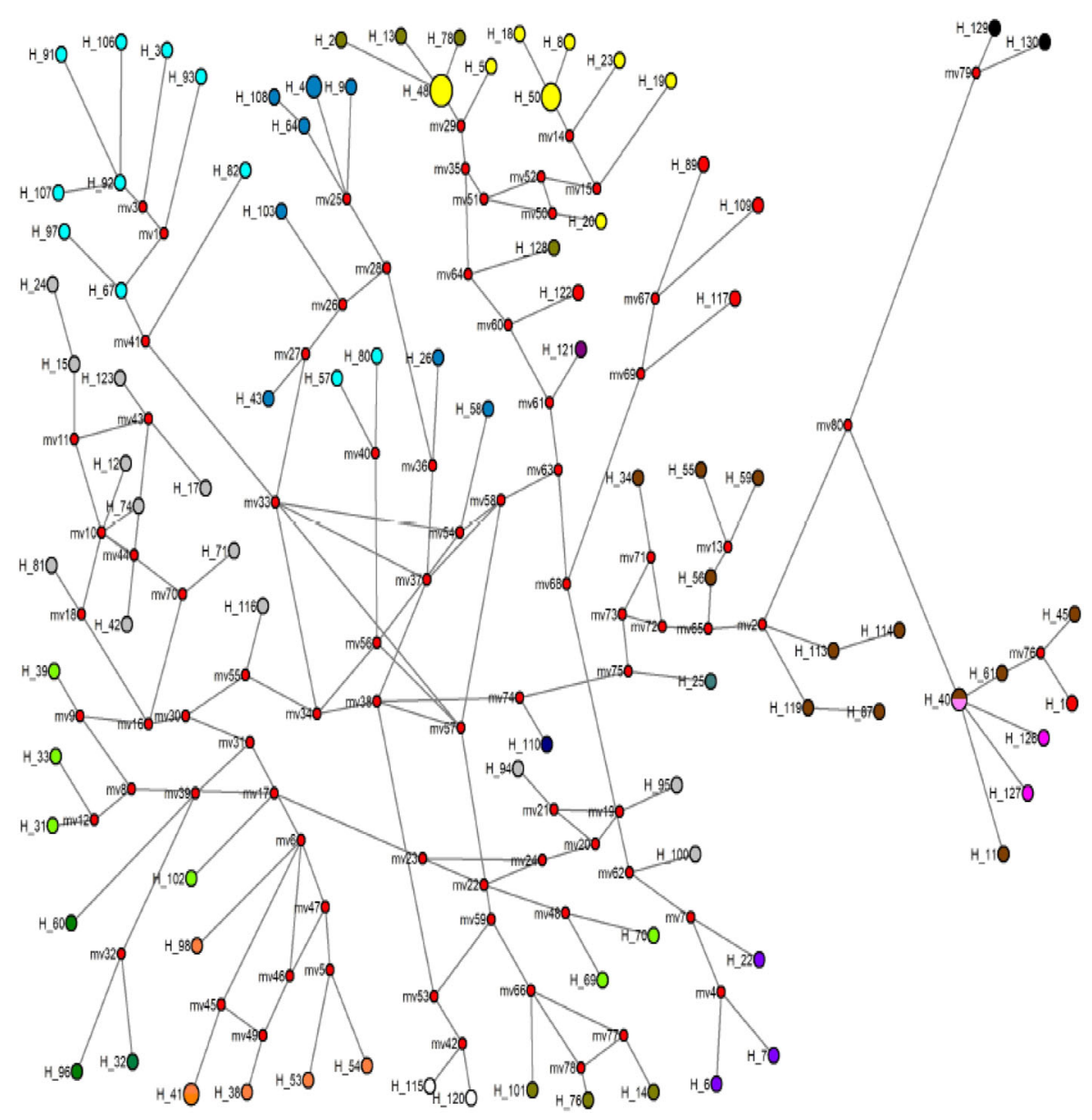

Fig. 4 Median joining network of mitogenome haplotypes for 136 Cebus albifrons, 2 C. olivaceus, 1 C. kaapori, 3 Cebus (Sapajus) apella, and 2 Saimiri albigena (as outgroups). Black circles = Saimiri albigena; pink circles $=$ Cebus $($ Sapajus $)$ apella ; brown circles = Cebus albifrons closely related to C. (Sapajus) apella in $\mathrm{H} 1, \mathrm{H} 2$, and $\mathrm{H} 3$; red circles $=C$. a. malitiosus; lilac circles $=C$. a. adustus; yellow circles $=C$. a . versicolor/ cesarae/pleei; brownish green circles $=C$. a. albifrons; blue-green circle = undescribed Peruvian C. albifrons subspecies; purple circle $=C$. a. trinitatis; white circles $=C$. olivaceus castaneus and $C$. olivaceus brunneus; navy-blue circle $=C$. kaapori; gray circles $=C$. albifrons $\mathrm{H} 4$; light green $=C$. albifrons $\mathrm{H} 5$; dark green $=$ C. albifrons $\mathrm{H6}$; orange circles $=C$. albifrons $\mathrm{H} 7$; light blue circles $=C$. albtifrons $\mathrm{H} 8$; blue circles $=$ C. albifrons H9. Red circles (with mv) indicate missing intermediate haplotypes.

tests in favor of population expansions. $\mathrm{H} 6$ and $\mathrm{H} 7$ showed no evidence of demographic changes.

\section{Spatial Genetic Structure}

The SAMOVAs applied to the mitogenomic data detected six different groups of Cebus albifrons in Ecuador (Table VII). This was fewer than in the previous analyses.

Geographical distance explained a nonsignificant $0.45 \%$ of the genetic distance between all the 49 Ecuadorian Cebus albifrons exemplars analyzed (Mantel test $(r=$ $0.067, P=0.121)$. 


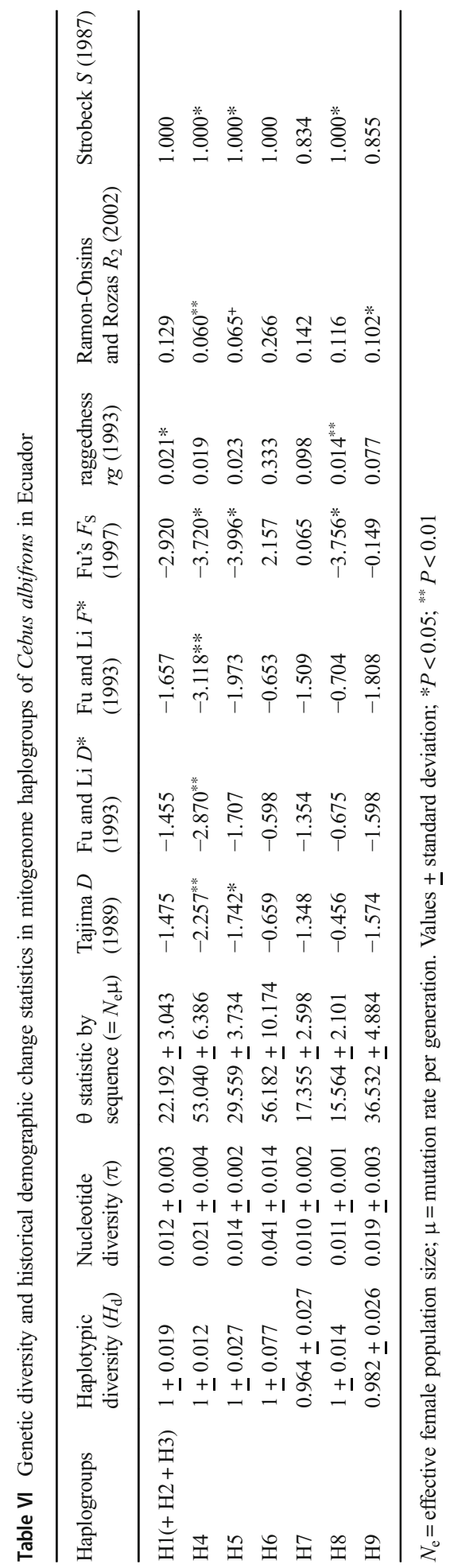


Table VII Results of spatial analysis of molecular variance for the mitogenomes of 49 Ecuadorian Cebus albifrons

\begin{tabular}{lll}
\hline Geographical clusters & $\%$ variance among groups & $\%$ variance within populations \\
\hline 2 groups & $12.72 \%$ & $77.28 \% * *$ \\
3 groups & $22.84 \% * *$ & $73.71 \% * *$ \\
4 groups & $19.43 \% * *$ & $80.29 \% * *$ \\
5 groups & $20.57 \% * *$ & $85.39 \% * *$ \\
6 groups & $32.06 \% * *$ & $83.41 \% * *$ \\
7 groups & $16.96 \%$ & $84.18 \% * *$ \\
\hline
\end{tabular}

$* * P<0.001$

Spatial autocorrelation analysis showed that the overall correlogram for all 10 distance classes was not significant $(V=0.00352, P=0.608$; Fig. 5). The two first distance classes were not significant. The third distance class $(121-181 \mathrm{~km})$ was negative and significant $(P=0.006)$, while the fourth distance class $(181-241 \mathrm{~km})$ was positive and significant $(P=0.001)$. The last distance class from 543 to $604 \mathrm{~km}$ also showed a positive increase in spatial autocorrelation, although not a significant one.

Monmonier's algorithm revealed six detectable geographical areas with genetic differences, although some of these areas included individuals from different haplogroups. In order of importance, the first barrier defined an area containing Manabí

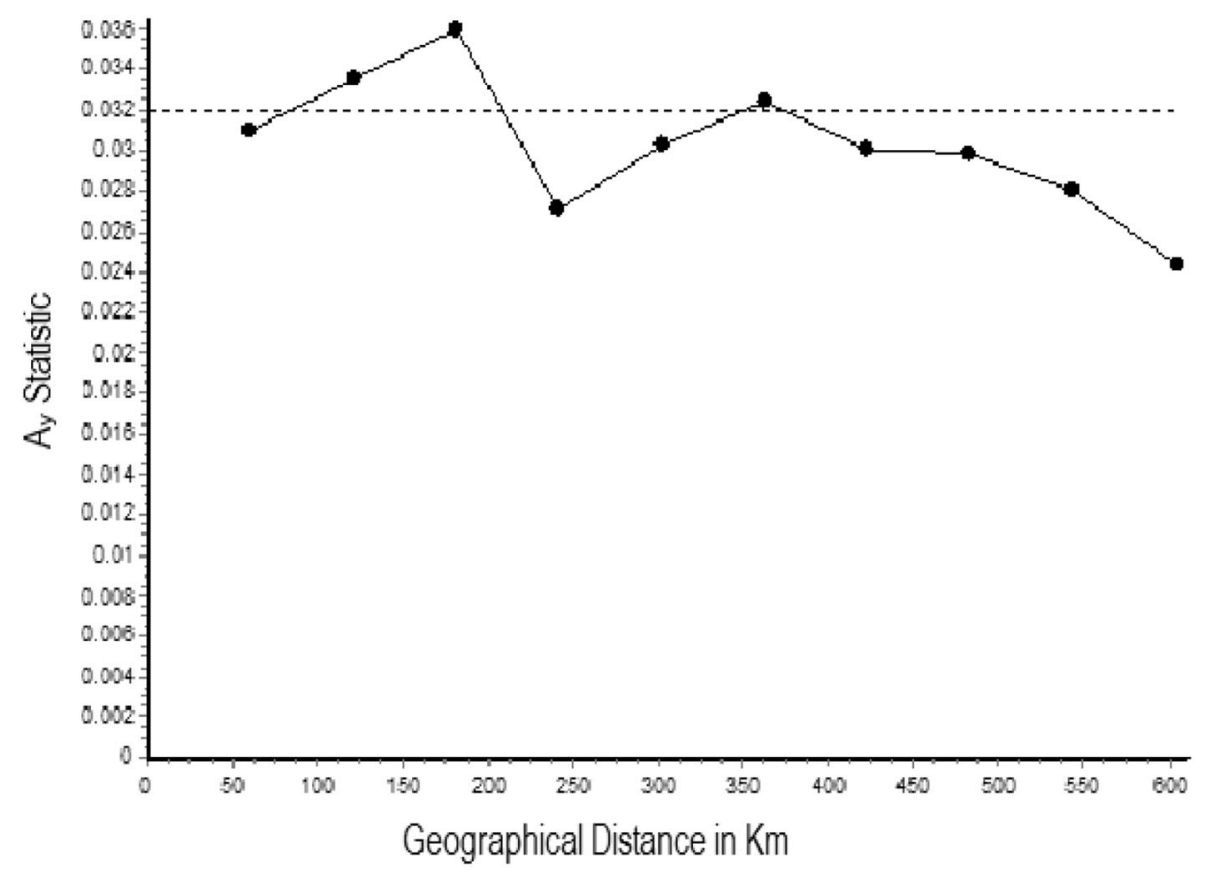

Fig. 5 Results of a spatial autocorrelation analysis for 49 Ecuadorian Cebus albifrons mitogenomes. 


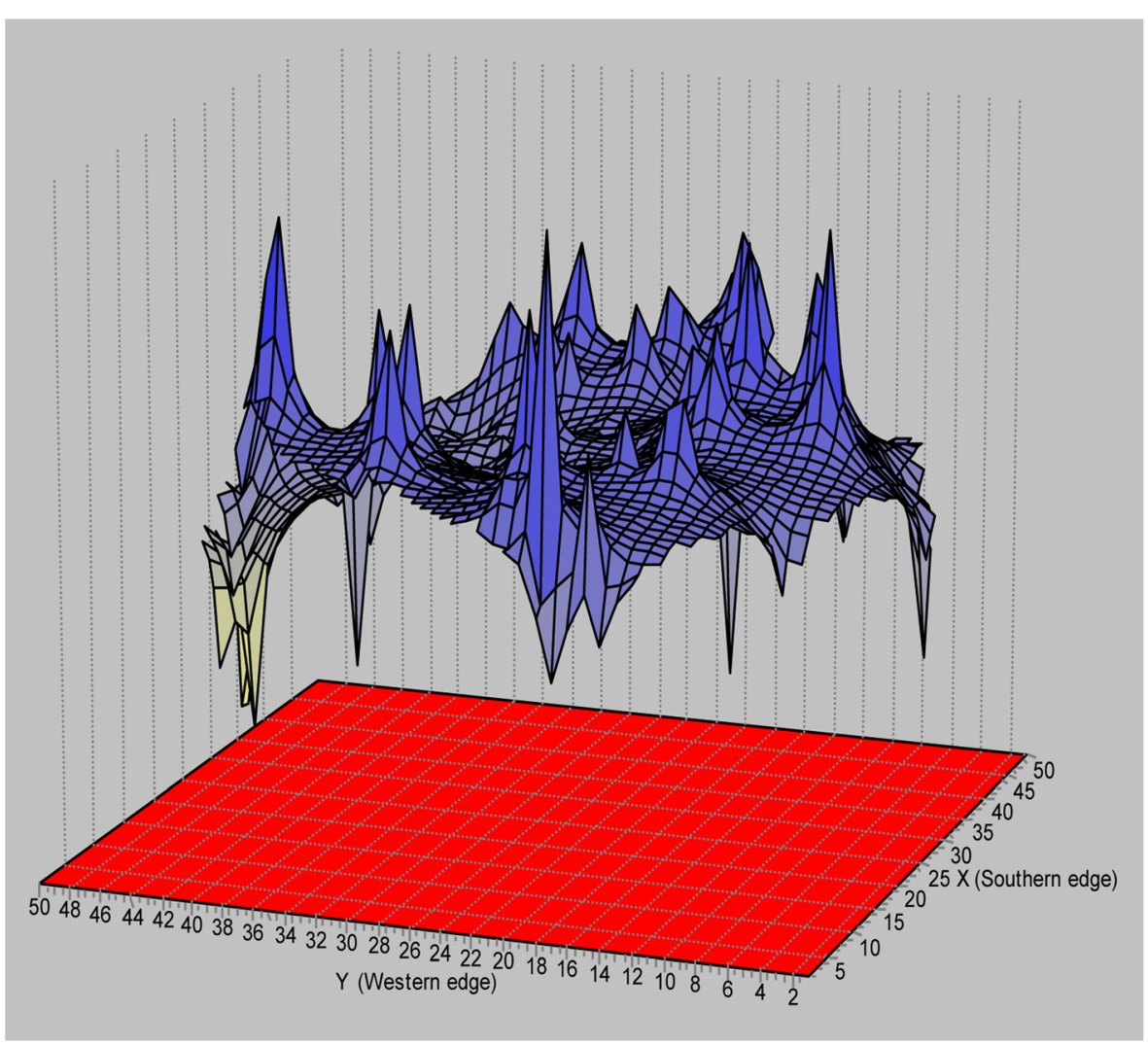

Fig. 6 Genetic landscape interpolation analysis for 49 Ecuadorian Cebus albifrons mitogenomes. $x$-axis $=$ southern limit of Ecuador; $y$-axis = western limit of Ecuador; $Z=$ genetic distances among mitogenomes of Ecuadorian Cebus albifrons.

Province (Pacific trans-Andean area) and Loja and Zamora-Chinchipe provinces in the southern Ecuadorian Amazon (cis-Andean area). The second barrier defined an Amazonian area where individuals from H1, H5, and $\mathrm{H} 7$ coexist. The third barrier formed a geographical area in the Pacific trans-Andean area related to Pichincha province (with several exemplars from the area of Santo Domingo de Tsáchilas). The fourth barrier was also in the Amazonian area and contained samples from H5 and H7. The fifth barrier described an area from the Pacific trans-Andean Ecuador, specifically from the Cotacachi-Cayapas Province. The sixth barrier described an area in the Ecuadorian Amazon, which included samples from H1, H3, and H5. Therefore, in the Pacific trans-Andean area, where only one unique taxon or lineage of Cebus albifrons (C. a. aequatorialis) was traditionally considered, we found three well-differentiated genetic lineages. One of these taxa extended to the cis-Andean Amazon area.

The genetic landscape interpolation analysis (Fig. 6) showed a high number of peaks and valleys distributed throughout Ecuador. This agrees quite well with the previous analyses, showing a considerable number of haplogroups within Ecuador. 


\section{Discussion}

We detected nine well differentiated haplogroups, some of which live in both trans- and cis-Andean areas of Ecuador. One haplogroup (H1), with the most divergent mitogenomes detected in Cebus albifrons, also contained haplotypes from C. (Sapajus) apella. The temporal mitochondrial diversification process for $C$. albifrons began in the Late Miocene and continued during the Pliocene and Pleistocene. All the detected haplogroups showed high levels of genetic diversity, which accords with their age and historically large size. Some haplotypes showed evidence of population expansion, but others did not. Spatial analyses detected these differentiated haplogroups, many of them were sympatrically distributed across Ecuador and did not show a significant spatial structure. Thus, we found no evidence of geographical regions in Ecuador with populations of $C$. albifrons with unique genetic characteristics, showing that the traditional systematics for $C$. albifrons in Ecuador, with two taxa, is inaccurate and oversimplified the evolutionary reality. We also showed that some haplogroups (H1 and H2), and exemplars of C. albifrons sampled at Vichada (eastern Colombian Llanos), were genetically very different from the other haplogroups of $C$. albifrons and to other gracile capuchin species.

\section{The Case of Cebus albifrons in Ecuador}

Traditionally, two taxa of Cebus albifrons have been described in Ecuador, Cebus albifrons aequatorialis, also known as C. aequatorialis, and C. a. yuracus, or C. yuracus. Of the two previous molecular studies with $C$. albifrons, only one included an exemplar of C. a. aequatorialis (Ruiz-García et al. 2010). Boubli et al. (2012) mentioned that $C$. a. aequatorialis may have originated from the $\mathrm{C} 2$ cluster they detected (composed of trans-Andean C. capucinus) or from the A cluster (C. albifrons of Amazonian origin) but did not provide the data necessary to test these hypotheses. However, the C. a. aequatorialis analyzed by Ruiz-García et al. (2010) clustered with exemplars of Amazonian $C$. albifrons. Our study includes many transAndean $C$. albifrons from Ecuador and suggests that this taxon has an Amazonian origin. We found the situation to be more complex than previously thought, even for a restricted and relatively small geographical area. Morphotypic and geographical information, traditionally used by primatologists, can hide the true evolutionary history of a species, which can be cryptic (Groves 2001, 2005). Based on mitogenomic analysis there are at least nine haplogroups in Ecuador. Only the SAMOVA detected a smaller number of haplogroups in Ecuador (six). There are two possible explanations for this. First, individuals from different haplogroups coexisted in the same geographical populations (SAMOVA only considers a unique population in a same geographical area), and this diminished the genetic differentiation among the geographical populations considered. Second, the SAMOVAs did not include exemplars of $C$. albifrons from other South American countries besides Ecuador. The inclusion of individuals of different origins help to discriminate haplogroups in Ecuador.

Haplogroup H1 included the most differentiated haplotypes of Cebus albifrons, including exemplars from the trans-Andean and cis-Andean Amazon in Ecuador. H1 also included haplotypes of $C$. (Sapajus) apella. The split between H1 and the remaining haplogroups of $C$. albifrons is estimated to have occurred around 5.59 
MYA (Bayesian Inference), or 4.14-3.22 MYA (median joining network). Thus, the divergence of the common ancestors of the Cebus lineage is dated to the Late Miocene and the Upper Pliocene. This agrees quite well with previous estimates of 4.2 MYA (Casado et al. 2010) and 5.52 MYA for Bayesian Inference and 3.31 MYA for median joining network (Ruiz-García et al. 2016a). The temporal estimate by Lynch-Alfaro et al. (2012) was a little higher (6.3 MYA). A previous study, with a high number of individuals and taxa of robust capuchins, found that the mtDNA of some C. albifrons are more similar to the robust capuchins than to other groups of $C$. albifrons, such as it was found here (Ruiz-García et al. 2016a). However, in no case was a robust capuchin included in the large clade of $C$. albifrons. These authors showed that the haplotypes of all robust capuchins were nested within the haplotypes of the gracile capuchins (mainly C. capucinus and C. albifrons). Taking into account these results, there are two possible hypotheses to explain the origin of $\mathrm{H} 1$. In one hypothesis, these exemplars descend from a hybridization between females of $C$. apella and males of $C$. albifrons. Then, the hybrids continuously bred with $C$. albifrons and their phenotypes are C. albifrons. In the second hypothesis, haplotypes of $C$. albifrons within $\mathrm{H} 1$ are some of the oldest in Cebus and they generated the mitochondrial haplotypes of the robust capuchins.

Four findings favor the second hypothesis. 1) The haplotypes of the robust capuchins were nested within the network of Cebus albifrons (Ruiz-García et al. 2016a). Moreover, the robust capuchins have considerably lower levels of genetic diversity than C. albifrons and C. capucinus, which suggests that gracile capuchins are older than robust capuchins. 2) There were no populations of $C$. apella, or other robust capuchins, in some areas where C. albifrons had mtDNA similar to robust capuchins. 3) mt haplotypes of C. albifrons from areas where $C$. apella were absent showed the most divergent haplotypes within H1. This indicates that they cannot be the product of a recent hybridization between gracile and robust capuchins. These haplotypes are older than the current haplotypes in the robust capuchins. 4) The geographic origins of the $C$. albifrons with haplotypes related to those of $C$. apella were very widely distributed, which does not suggest sporadic and recent hybridization events between these two taxa in specific geographical points. Nonetheless, two haplotypes of C. albifrons (one from Pastaza, Ecuador, and other from Puerto Rastrojo, Amazonas, Colombia) and those from $C$. apella were highly related, and could represent two cases of relatively recent hybridization with introgression in $C$. albifrons. Thus, although both scenarios are plausible, the second hypothesis seems to be the most likely.

$\mathrm{H} 2$ provides additional evidence in favor of the second hypothesis. It has a unique exemplar with a very differentiated haplotype in the Pichincha province (trans-Andean area), but more related to the mixed $\mathrm{H} 1$ than to the other Ecuadorian haplogroups. The trans-Andean $C$. albifrons contained in $\mathrm{H} 1$ and $\mathrm{H} 2$ may represent the first, or the first two colonizations of the trans-Andean Pacific area coming from the western Amazon.

$\mathrm{H} 3$ is very interesting because it contained one exemplar from the Amazonian Pastaza province and a Cebus albifrons malitiosus from northern Atlantic Colombia. They are $2000 \mathrm{~km}$ apart. Some of the oldest haplotypes of the Amazonian C. albifrons migrated toward the eastern Amazon and the Atlantic Brazilian coast and gave rise to the robust capuchins, but they also migrated toward northern South America to give rise to the first, and oldest, group of C. albifrons in that area: C. a. malitiosus. However, this old Amazonian lineage in the north Atlantic part of Colombia hybridized with one lineage of $C$. capucinus that had extensive introgression in this old Amazonian group and generated the current C. a. malitiosus (Ruiz-García et al. 2018). 
H4 corresponds to Cebus albifrons yuracus. It expanded to the entire Ecuadorian Amazon as well as to a large fraction of the Peruvian, Colombian, and western Brazilian Amazon. However, C. a. yuracus does not explain all the genetic variability found in the Ecuadorian Amazon for C. albifrons. For instance, H5 and $\mathrm{H} 7$ were not included in $\mathrm{H} 4$, although they could also contain exemplars a priori described as C. a. yuracus.

H6 was another small haplogroup composed of one trans-Andean Pacific exemplar and two exemplars from the central Ecuadorian Amazon. This haplogroup probably shows the existence of a second or third migration from the Amazon to the transAndean Pacific area. This migration would have occurred more recently than those detected from $\mathrm{H} 1$ and $\mathrm{H} 2$.

$\mathrm{H} 8$ is a monophyletic group with the majority of the trans-Andean Pacific exemplars, but also contained animals from different Amazonian areas, especially from the central-southern Ecuadorian Amazon. If Cebus albifrons originated in the Amazon, then $\mathrm{H} 8$ originated from the southern Ecuadorian Amazon area (the subcluster had three exemplars from the Loja and Zamora-Chinchipe provinces). It may represent a fourth migration from the Amazon to the trans-Andean Pacific area and the most successful of all migrations from the Amazon to trans-Andean Ecuador. The two subclusters of H8 split around 2.43 MYA and the major subcluster diversified around 1.91 MYA. This coincides with the Gelasian (2.5-1.8 MYA), a period characterized by the last stages of a global cooling trend that led to the Pleistocene ice age (ICS 2007). However, it is possible that some part of this trans-Andean C. albifrons population migrated later toward the central-southern Ecuadorian area (some exemplars from the Pastaza and Loja provinces). If this is true, a fifth migration (or various small migrations) for this species crossed the Andean cordillera in Ecuador toward the Amazon fairly recently (0.28-0.1 MYA). In either case, the Andean cordillera did not genetically isolate the populations of $C$. albifrons on both sides of that mountain range. This does not support a unique taxon named C. a. aequatorialis (and less $C$. aequatorialis) in the trans-Andean Pacific Ecuador. At a minimum, exemplars from H1, H2, H6, and H8, which are polyphyletic and arrived in the trans-Andean Pacific area at different times, are present in that zone of Ecuador. Similarly, MMDA showed three different genetic pools in the trans-Andean Pacific area. H2 was not differentiated because it was in the same geographical area as other Pichincha individuals. Ecuador is a small country and humans have likely transported individuals of $C$. albifrons across the Andean cordillera since prehistoric times. However, all the temporal splits of trans- and cis-Andean individuals of $C$. albifrons, are older than 100,000 years, well before the arrival of humans in South America.

H9 included one individual from the central Ecuadorian Amazon, which had the oldest sign of diversification (excluding H1) detected in Ecuador (3.76 MYA). This exemplar, and another less genetically differentiated one, were related to the individuals at Tefé Lake in the central Brazilian Amazon, where the holotype of C. a. unicolor was defined. They were also related to individuals from southern Peru and Bolivia, which are classified as C. a. cuscinus. Therefore, molecularly, there was no clear differentiation between $C$. a. unicolor and C. a. cuscinus. $\mathrm{H} 9$ was the original Ecuadorian haplogroup (from central Ecuadorian Amazon) that resulted in the largest expansion by the western and central Amazon.

Many exemplars of Cebus albifrons sampled in the Ecuadorian Amazon were related to lineages of $C$. albifrons distributed throughout the rest of the Amazon basin. 
These areas cover the northern, central, and southern Peruvian Amazon, northern Bolivian Amazon, Colombian Amazon, and western and central Brazilian Amazon. Many of these non-Ecuadorian animals are restricted to one haplogroup. C. albifrons, from the current Ecuadorian Amazon, was an exception and present in at least nine haplogroups. No exemplars from other Amazonian countries belonged to such a high number of haplogroups. This agrees quite well with the premise that the oldest lineages of $C$. albifrons originated in the Ecuadorian Amazon (the most western Amazonian area). From here, C. albifrons expanded and colonized other Amazonian areas. The Ecuadorian Amazon was also the point of origin for $C$. albifrons in northern South America (Colombia, Venezuela, and the Trinidad Island in the Caribbean Sea).

Other results suggest that the original haplogroups of Cebus albifrons are Ecuadorian. The nucleotide diversity within the Ecuadorian haplogroups $(\pi=0.011-0.041)$ are considerably greater than estimates for other haplogroups of $C$. albifrons, suggesting that the Ecuadorian haplogroups are older. This also agrees quite well with the fact that other species of mammals began their expansions in South America from the western Amazon (capybara, Hydrochoerus hydrochaeris: Ruiz-García et al. 2016c; jaguar, Panthera onca: Ruiz-García et al. 2013a; otters, Lontra longicaudis and Pteronura brasiliensis: Ruiz-García et al. 2017; squirrel monkeys, Saimiri sp.: Ruiz-García et al. 2015; lowland tapir, Tapirus terrestris: Ruiz-García et al. 2016d).

Temporal diversification among and within some of the Ecuadorian haplogroups began in the Middle Pliocene (diversification within H1, within H9, and the splits between $\mathrm{H} 4+\mathrm{H} 5$ and $\mathrm{H} 6+\mathrm{H} 7$ ). These time splits coincide with a large peak in diversification within many vertebrate taxa during the Pliocene. The cold and dry climate during the Pliocene coincides with the onset of high latitude glacial cycles, causing an explosive expansion of low-biomass vegetation, including grasslands and steppe at mid-latitudes and development of taiga at high latitudes of Eurasia and North America. This coincided with climatic changes that developed from the completion of the Panamanian land bridge (3.5-2.8 MYA; Coates and Obando 1996; Marshall 1985, 1988; Marshall et al. 1979, 1982; Webb 1985, 1991) in the Middle Pliocene. The diversification within the remaining Ecuadorian haplogroups (2.66-1.65 MYA) could be explained by the Gelasian period and the beginning of the Pleistocene when there was a clear decrease in temperature $\left(5^{\circ} \mathrm{C}\right)$ and rain levels (Van der Hammen 1975). These periods were also very important for the genetic diversification of many other Neotropical mammals (Ruiz-García and Pinedo-Castro 2013; Ruiz-García et al. 2013b).

These temporal splits, along with population expansion data for H4, H5, H8, and H9, strongly suggest that Pleistocene refuges and hence the Pleistocene refuge hypothesis (Haffer 1969, 1997, 2008) were important to the divergence and diversification of the haplogroups of the Ecuadorian Cebus albifrons. This hypothesis proposes the existence of recurring phases of continuous rainforest alternating with drier, fragmented savannas throughout the Amazon. These wet-dry cycles occurred in intervals of 20,000 $\mathrm{Y}$ and especially affected the border areas of the Amazon (Van der Hammen and Hooghiemstra 2000), such as the Ecuadorian Amazon. This hypothesis was originally established for the Pleistocene, but later expanded to the Miocene-Pliocene periods as well (Haffer 1997, 2008). It may explain why different haplogroups of C. albifrons live in sympatry without the existence of physical barriers. During dry cycles, different C. alibifrons were isolated and differentiated from each other. However, during wet cycles, these populations expanded and became sympatric, possibly without 
reproductive isolation. This process occurred many times. The Recent Lagoon hypothesis, which proposes the existence of an internal lake or lagoons (Amazon Lake) during the Pliocene and Pleistocene (Campbell 1990; Frailey et al. 1988; Hubert and Renno 2006; Hubert et al. 2007; Klammer 1984; Marroig and Cerqueira 1997; Nores 1999, 2004) predicts similar effects on the genetic differentiation of haplotypes of C. albifrons. A marine incursion may have occurred around 4-5 MYA (Hubert and Renno 2006; Nores 1999) with a $100 \mathrm{~m}$ rise in global sea level. At around 2.5 MYA (Wesselingh and Hoorn 2011), glacio-eustatic oscillations existed in cycles of around 40,000-100,000 Y, coinciding with global sea-level oscillations (up to about $120 \mathrm{~m}$ ), which would have created inner lagoons within the Amazon. Aleixo and de Fatima Rossetti (2007) claimed that the midwestern Amazon may be the most dynamic area for new colonization, owing to a relatively recent reduction of the Amazon Lake and subsequent floodplains in that area. However, some authors have resisted this view (Haffer 2008; Marshall and Lundberg 1996; Miller et al. 2005; Paxton et al. 1996; Tuomisto et al. 1992). Regardless of which hypothesis prevails, it is difficult to apply the typical Linnaean nomenclature below the species level for $C$. albifrons. The phylogenetic evidence does not support the existence of two subspecies (C. $a$. aequatorialis and C. a. yuracus) in Ecuador.

\section{Insights into the Systematics of Cebus albifrons}

The exemplars of Cebus albifrons from the Vichada Department (Eastern Llanos, Colombian Orinoco River) showed strong evidence of a possible subspecies. This group showed genetic distances considerably higher $(>6 \%)$ than to other C. albifrons taxa and lives in a specific geographical area. If so, this is the true C. a. albifrons and is a different taxon to $C$. a. unicolor, contra the hypotheses of Defler and HernándezCamacho (2002) and Defler (2003), who synonymized C. a. albifrons and C. a. unicolor. The group from Vichada was not part of the B2 group defined by Boubli et al. (2012) for a relatively nearby geographical area (Venezuela and Guyana Shield).

Another interesting difference between our findings and those of Boubli et al. (2002) is that they detected only one taxon on Trinidad Island (C. o. brunneus that they named C. brunneus). We detected two different morphotypes (photos are available from M. R$\mathrm{G})$ and two clearly different molecular phylogenetic branches for the exemplars of this Caribbean Island. One is consistent with C. o. brunneus (maybe recently introduced by humans) and another paler yellow morphotype which corresponds to the true $C$. $a$. trinitatis. This suggests that C. a. trinitatis is not a junior synonym of C. o. brunneus, as hypothesized by Boubli et al. (2012).

Our study included only two Cebus olivaceus (one C. o. brunneus from Trinidad Island, and one C. o. castaneus from the mouth of the Amazon River in Brazil). Following Boubli et al. (2012), these are the two most differentiated full species (C. brunneus and C. castaneus) of the C. olivaceus group. However, our analyses showed that they are very similar when many diversified haplotypes of $C$. albifrons are analyzed. Thus, none of our findings support the hypotheses of Boubli et al. (2012).

Our results suggest that Cebus kaapori should be a full subspecies of the complex of gracile capuchins and maybe even a full species, although the genetic distances with other taxa of gracile capuchins were not very large. It has a differentiated morphology and a geographic distribution that is isolated from the other gracile capuchins. Some 
analyses showed that its mitochondria are closer to those of the haplogroup of the robust capuchins or, at least, to the oldest haplotypes of $C$. albifrons which gave rise to the robust capuchins (maximum likelihood tree and genetic distances: $4.1 \%$ with the $\mathrm{H} 1$ and $6.4 \%$ with $C$. olivaceus). Nonetheless, the Bayesian Inference showed $C$. kaapori to be more related to the C. o. castaneus (Pará State) such as claimed by Boubli et al. (2012). Thus, more individuals of C.o. castaneus and C. kaapori should be studied from a genetic perspective to determine their exact phylogenetic relationship.

\section{Are There Different Species of Cebus albifrons?}

Bobli et al. (2012) concluded that the four traditional (pelage) species of gracile capuchins (Cebus albifrons, C. capucinus, C. kaapori, and C. olivaceus) could be assigned to 12 different species, with $C$. albifrons divided into at least six species (C. adustus, C. albifrons, C. cesarae, C. versicolor, C. unicolor, and C. yuracus). Three lines of biological and evolutionary argument suggest that this proliferation of species is not supported. 1) We found that some important geographical barriers (such as the Ecuadorian Andes and the Amazon) did not genetically isolate populations of $C$. albifrons. The lack of reproductive isolation may explain the small differences in the coat characteristics of $C$. $a$. aequatorialis and C. a. yuracus (Van Roosmalen and Van Roosmalen 2013). 2) We have observed crosses between diverse taxa of $C$. albifrons in the wild and in captivity (unpubl. data). Examples include yuracus $\times$ aequatorialis, yuracus $\times$ unicolor, versicolor $\times$ unicolor, versicolor $\times$ cesarae. The descendants were fertile and became reproductively integrated in some of the parental groups. There are multiple examples of broad and extensive interbreeding between the gracile capuchins in the contact areas of $C$. albifrons and C. capucinus (Hernández-Camacho and Cooper 1976; Ruiz-García et al. 2016a). The fact that this hybridization (both within $C$. albifrons and between $C$. albifrons and C. capucinus) is common is strong evidence of a lack of reproductive isolation mechanisms for these gracile capuchins. The strong chromosomal homogeneity, both autosomic and sexual (Amaral et al. 2008), among these taxa of gracile capuchins agrees with the lack of reproductive barriers among them. Similarly, analysis of nuclear DNA microsatellites, including the proposed species, C. capucinus and C. imitator (Boubli et al. 2012), the proposed species of robust capuchins (C. apella fatuellus, C. macrocephalus, and C. libidinosus pallidus), and with the proposed species of gracile capuchins in northern Colombia (C. versicolor, C. adustus, and C. cesarae: Boubli et al. 2012), showed high levels of nuclear gene flow among these supposedly differentiated species (Ruiz-García and Castillo 2016; Ruiz-García et al. 2016b, 2018). 3) The genetic distances we obtained for among different taxa of $C$. albifrons are clearly below the species level and often below the subspecies level. The genetic distances among $\mathrm{H} 4$ (the most related to yuracus), H8 (the most related to aequatorialis), and $\mathrm{H} 9$ (the most related to unicolor-cuscinus) were around $3 \%$. These values were below the subspecies boundary and very far from the species limit. When $\mathrm{H} 4, \mathrm{H} 8$, and $\mathrm{H} 9$ were compared with the taxa of $C$. albifrons from northern Colombia and Trinidad Island, these values were also around 3\%. These three Ecuadorian haplogroups showed only ca. $2.5 \%$ when compared with a traditionally considered, fully differentiated species such as C. olivaceus. Additionally, these three Ecuadorian haplogroups showed around $4.2 \%$, with C. kaapori, another traditionally accepted, fully differentiated species. The last value is only slightly over the subspecies boundary. 
One of the main arguments provided to explain the high number of gracile capuchin species is that the evolution of the group began around 2.5 MYA, and consequently, there was a considerable amount of time for divergence (Boubli et al. 2012). However, this is insufficient for speciation when there is a high and repetitive level of nuclear gene flow in times of population expansion during the wet period cycles. mt haplotypes diverged at some point during population fragmentation, when populations contract during the dry period cycles. Studies of nuclear microsatellites support this hypothesis (Ruiz-García and Castillo 2016; Ruiz-García et al. 2016b, 2018). The maternal mitochondrial lineages may have differentiated long ago, but the males could have been genetic vectors of connection between those differentiated maternal lineages especially during the wet periods.

Based on our findings, Cebus albifrons (together with C. capucinus, C. olivaceus, and even $C$. kaapori) formed a complex of populations and subspecies. Their populations experienced repetitive fission-fussion events with complex and reticulated high levels of gene flow. These events and gene flow prevented speciation (Ruiz-García 1990, 1991). Future studies should analyze nuclear (autosomic and Y chromosome) gene sequences to understand the degree of hybridization among all of the gracile capuchin taxa.

When we analyze relatively small samples isolated by relatively large distances, it is easy to find well-structured genetic groups (Boubli et al. 2012). Additionally, it is easy to apply the Linnaean nomenclature and the phylogenetic species concept with a molecular typological point of view. For example, Boubli et al. (2012) found one unique haplogroup (named A) for the Ecuadorian Amazon and a large part of the Peruvian Amazon. However, we detected nine different haplogroups in the Ecuadorian Amazon living sympatrically in many cases with a considerably larger sample of Cebus albifrons. Nevertheless, if many exemplars are analyzed covering many geographical areas, and taking into account the existence of possible hybridization and a broad Biological Species Concept (in the sense of Coyne and Orr 2004), it is clear that the application of the Linnaean nomenclature and the phylogenetic species concept does not reflect the much more complex reality.

We recommend that all the populations of white-fronted capuchins from Ecuador be known as Cebus albifrons, and that the use of subspecific names be avoided. We hope that with broader and more comprehensive sampling of gracile capuchins in the future will improve our understanding of their intraspecific systematics.

Acknowledgments We thank Dr. Diana Alvarez, Pablo Escobar-Armel, Nicolás Lichilín, Luisa Fernanda Castellanos-Mora, Armando Castellanos, Andrés Laguna, and Lina Argüello for their respective help in obtaining capuchin samples during the last 20 years. We thank Dr. Horacio Schneider and Dr. Iracilda Sampaio for providing DNA samples of Cebus olivaceus and Cebus kaapori. We express our appreciation to the Ministerio del Ambiente Ecuatoriano (MAE) in Santo Domingo de Tsáchilas and in Coca, the Instituto von Humboldt (Colombia), the Peruvian Ministry of Environment, PRODUCE (Dirección Nacional de Extracción y Procesamiento Pesquero), Consejo Nacional del Ambiente and the Instituto Nacional de Recursos Naturales (INRENA) from Peru, the Colección Boliviana de Fauna (Dr. Julieta Vargas), and CITES Bolivia for their role in facilitating the obtainment of the collection permits in Ecuador, Colombia, Peru, and Bolivia. We extend special thanks to the many people of diverse Indian tribes in Ecuador (Kichwa, Huaorani, Shuar, and Achuar), in Colombia (Jaguas, Ticunas, Huitoto, Cocama, Tucano, Nonuya, Yuri, and Yucuna), in Peru (Bora, Ocaina, Shipigo-Comibo, Capanahua, Angoteros, Orejón, Cocama, Kishuarana, and Alamas), and Bolivia (Sirionó, Canichana, Cayubaba, and Chacobo) for their assistance in obtaining samples of white-faced capuchins. We also acknowledge the editor and reviewers for their suggestions to improve the quality of the manuscript. 


\section{References}

Akaike, H. (1974). A new look at the statistical model identification. IEEE Transactions on Automatic Control, 19, 716-723.

Aleixo, A., \& de Fatima Rossetti, D. (2007). Avian gene trees, landscape evolution, and geology: towards a modern synthesis of Amazonian historical biogeography? Journal of Ornithology, 148(Suppl. 2), S443-S453.

Amaral, P. J. S., Finotelo, L. M. F., De Oliveira, E. H. C., Pissinatti, A., Nagamachi, C. Y., \& Pieczarka, J. C. (2008). Phylogenetic studies of the genus Cebus (Cebidae-Primates) using chromosome painting and Gbanding. BMC Evolutionary Biology, 8, 169.

Ascunce, M. S., Hasson, E., \& Mudry, M. D. (2003). COII: A useful tool for inferring phylogenetic relationships among New World monkeys (Primates, Platyrrhini). Zoologica Scripta, 32, 397-406.

Ashley, M. V., \& Vaughn, T. A. (1995). Owl monkeys (Aotus) are highly divergent in mitochondrial cytochrome c oxidase (COII) sequences. International Journal of Primatology, 16(5), 793-807.

Avise, J. C. (1994). Molecular markers, natural history, and evolution. New York: Chapman and Hall.

Avise, J. C., Arnold, J., Ball, R. M., Bermingham, E., Lamb, T., et al (1987). Intraspecific phylogeographic: the mitochondrial DNA bridge between population genetics and systematics. Annual Review of Ecology and Systematics, 18, 489-522.

Bandelt, H. J., Forster, P., \& Rohl, A. (1999). Median-joining networks for inferring intraspecific phylogenies. Molecular Biology and Evolution, 16, 37-48.

Bensasson, D., Zhang, D.-X., Hartl, D. L., \& Hewitt, G. M. (2001). Mitochondrial pseudogenes: evolution's misplaced witnesses. Trends in Ecology \& Evolution, 16, 314-321.

Boubli, J. P., Rylands, A. B., Farias, I. P., Alfaro, M. E., \& Lynch-Alfaro, J. W. (2012). Cebus phylogenetic relationships: a preliminary reassessment of the diversity of the untufted capuchin monkeys. American Journal of Primatology, 74, 381-393.

Bradley, R. D., \& Baker, R. J. (2001). A test of the genetic species concept: cytochrome-b sequences and mammals. Journal of Mammalogy, 82, 960-973.

Brouns, G., De Wulf, A., \& Constales, D. (2003). Delaunay triangulation algorithms useful for multibeam echosounding. Journal of Surveying Engineering, 129, 79-84.

Campbell, K. E. (1990). The geologic basis of biogeographic patterns in Amazonia. In G. Peters \& R. Hutterer (Eds.), Vertebrates in the tropics (pp. 33-43). Bonn: Alexander Koenig Zoological Research Institute.

Casado, F., Bonvicino, C. R., Nagle, C., Comas, B., Manzur, T. D., et al (2010). Mitochondrial divergence between 2 populations of the hooded capuchin, Cebus (Sapajus) cay (Platyrrhini, Primates). Journal of Heredity, 101, 261-269.

Coates, A. G., \& Obando, J. A. (1996). The geologic evolution of the central American isthmus. In J. B. C. Jackson, A. F. Budd, \& A. G. Coates (Eds.), Evolution and environment in tropical America (pp. 21-56). Chicago: University of Chicago Press.

Collins, A. C., \& Dubach, J. M. (2000). Phylogenetic relationships of spider monkeys (Ateles) based on mitochondrial DNA variation. International Journal of Primatology, 21, 381-420.

Coyne, J. A., \& Orr, H. A. (2004). Speciation. Sunderland, MA: Sinauer Associates.

Cracraft, J. (1983). Species concepts and speciation analysis. In R. J. Johnston (Ed.), Current ornithology (Vol. I, pp. 158-187). New York: Plenum Press.

Cracraft, J. (1989). Speciation and its ontology: The empirical consequences of alternative species concepts for understanding patterns and processes of differentiation. In D. Otte \& J. Endler (Eds.), Speciation and its consequences (pp. 28-59). Sunderland, MA: Sinauer Associates.

de Silva, J.S. (2001). Especiacao nos macacos-pregos e caiararas, género Cebus Erxleben, 1777 (Primates, Cebidae) (pp. 1-377). Doctoral thesis, Universidade Federal do Rio de Janeiro.

Defler, T. R. (2003). Primates de Colombia. Bogotá: Conservación Internacional.

Defler, T. R., \& Hernández-Camacho, J. I. (2002). The true identity and characteristics of Simia albifrons Humboldt, 1812: description of neotype. Neotropical Primates, 10, 49-64.

Drummond, A. J., Ho, S. Y. W., Phillips, M. J., \& Rambaut, A. (2006). Relaxed phylogenetics and dating with confidence. PLoS Biology, 4, e88.

Drummond, A. J., Suchard, M. A., Xie, D., \& Rambaut, A. (2012). Bayesian phylogenetics with BEAUti and the BEAST 1.7. Molecular Biology and Evolution, 29, 1969-1973.

Dupanloup, I., Schneider, S., \& Excoffier, L. (2002). A simulated annealing approach to define the genetic structure of populations. Molecular Ecology, 11, 2571-2581.

Erixon, P., Svennblad, B., Britton, T., \& Oxelman, B. (2003). Reliability of Bayesian posterior probabilities and bootstrap frequencies in phylogenetics. Systematic Biology, 52, 665-673. 
Excoffier, L., \& Lischer, H. E. L. (2010). Arlequin suite ver 3.5: a new series of programs to perform population genetics analyses under Linux and windows. Molecular Ecology Resources, 10, 564-567.

Frailey, C. D., Lavina, E. L., Rancy, A., \& Pereira de Souza, J. (1988). A proposed Pleistocene/Holocene lake in the Amazon Basin and its significance to Amazonian geology and biogeography. Acta Amazonica, 18, 119-143.

Fu, Y. X. (1997). Statistical tests of neutrality against population growth, hitchhiking and background selection. Genetics, 147, 915-925.

Fu, Y. X., \& Li, W. H. (1993). Statistical tests of neutrality of mutations. Genetics, 133, 693-709.

Galtier, N., Enard, D., Radondy, Y., Bazin, E., \& Belkhir, K. (2006). Mutation hotspots in mammalian mitochondrial DNA. Genome Research, 16, 215-222.

Groves, C. P. (2001). Primate taxonomy. Washington, DC: Smithsonian Institution Press.

Groves, C. P. (2005). Order primates. In D. E. Wilson \& D. M. Reeder (Eds.), Mammal species of the world: A taxonomic and geographic reference (pp. 111-184). Baltimore: Johns Hopkins University Press.

Guschanski, K., Krause, J., Sawyer, S., Valente, L. M., Bailey, S., et al (2013). Next-generation museomics disentangles one of the largest primate radiations. Systematic Biology, 62, 539-554.

Haffer, J. (1969). Speciation in Amazonian forest birds. Science, 165, 131-137.

Haffer, J. (1997). Alternative models of vertebrate speciation in Amazonia: an overview. Biodiversity and Conservation, 6, 451-476.

Haffer, J. (2008). Hypotheses to explain the origin of species in Amazonia. Brazilian Journal of Biology, 68, 917-947.

Haig, S. M. (1998). Molecular contributions to conservation. Ecology, 79, 413-425.

Harpending, H. (1994). Signature of ancient population growth in a low resolution mitochondrial DNA mismatch distribution. Human Biology, 66, 591-600.

Harpending, H. C., Sherry, S. T., Rogers, A. R., \& Stoneking, M. (1993). Genetic structure of ancient human populations. Current Anthropology, 34, 483-496.

Hebert, P. D. N., Cywinska, A., Ball, S. L., \& de Waard, J. R. (2003). Biological identifications through DNA barcodes. Proceedings of the Royal Society of London B: Biological Sciences, 270, 313-321.

Hebert, P. D. N., Stoeckle, M. Y., Zemlak, T. S., \& Francis, C. M. (2004). Identification of birds through DNA barcodes. PLoS Biology, 2, 1657-1663.

Hernández-Camacho, J., \& Cooper, R. W. (1976). The nonhuman primates of Colombia. In R. W. Thorington Jr. \& P. G. Heltne (Eds.), Neotropical primates: Field studies and conservation (pp. 35-69). Washington, DC: National Academy of Sciences.

Hershkovitz, P. (1949). Mammals of northern Colombia. Preliminary report n 4: Monkeys (Primates), with taxonomic revisions of some forms. Proceedings of the United States National Museum, 98, 323-427.

Hillis, D. M., \& Bull, J. J. (1993). An empirical test of bootstrapping as a method for assessing confidence in phylogenetic analysis. Systematic Biology, 42, 182-192.

Hubert, N., \& Renno, J. F. (2006). Historical biogeography of south American freshwater fishes. Journal of Biogeography, 33, 1414-1436.

Hubert, N., Duponchelle, F., Nunez, J., Garcia-Davila, C., Paugy, D., \& Renno, J. F. (2007). Phylogeography of the piranha genera Serrasalmus and Pygocentrus: Implications for the diversification of the Neotropical ichthyofauna. Molecular Ecology, 16, 2115-2136.

Hudson, R. R., Boss, D. D., \& Kaplan, N. L. (1992). A statistical test for detecting population subdivision. Molecular Biology and Evolution, 9, 138-151.

Huelsenbeck, J. P., \& Rannala, B. (2004). Frequentist properties of Bayesian posterior probabilities of phylogenetic trees under simple and complex substitution models. Systematic Biology, 53, 904-913.

International Commission on Stratigraphy (2007). International Stratigraphic Chart. http://www.sratigraphy. org/chus.pdf.

Janson, C. H., \& Emmons, L. H. (1990). Ecological structure of the nonflying mammal community at Cocha Cashu Biological Station, Manu National Park, Peru. In A. H. Gentry (Ed.), Four Neotropical forests (pp. 314-338). New Haven: Yale University Press.

Kartavtsev, Y. (2011). Divergence at $C y t-b$ and $C o-1$ mtDNA genes on different taxonomic levels and genetics of speciation in animals. Mitochondrial DNA, 22, 55-65.

Kimura, M. (1980). A simple method for estimating evolutionary rates of base substitutions through comparative studies of nucleotide sequences. Journal of Molecular Evolution, 16, 111-120.

Klammer, G. (1984). The relief of the extra-Andean Amazon basin. In H. Sioli (Ed.), The Amazon: Limnology and landscape ecology of a mighty tropical river and its basin (pp. 47-83). Dordrecht: Junk Publishers.

Lanave, C. G., Preparata, C., \& Saccone, C. (1984). A new method for calculating evolutionary substitution rates. Journal of Molecular Evolution, 20, 86-93. 
Librado, P., \& Rozas, J. (2009). DnaSP v5: a software for comprehensive analysis of DNA polymorphism data. Bioinformatics, 25, 1451-1452.

Lynch-Alfaro, J. W., De Souza, E., Silva Jr., J., \& Rylands, A. B. (2012). How different are robust and gracile capuchin monkeys? An argument for the use of Sapajus and Cebus. American Journal of Primatology, 74, 273-286.

MacFadden, B. J. (1990). Chronology of Cenozoic primate localities in South America. Journal of Human Evolution, 19, 151-156.

Manel, S., Schwartz, M. L., Luikart, G., \& Taberlet, P. (2003). Landscape genetics: Combining landscape ecology and population genetics. Trends in Ecology \& Evolution, 18, 189-197.

Manni, F., Guerard, E., \& Heyer, E. (2004). Geographic patterns of (genetic, morphologic, linguistic) variation: how barriers can be detected by using Monmonier's algorithm. Human Biology, 76, 173-190.

Mantel, N. A. (1967). The detection of disease clustering and a generalized regression approach. Cancer Research, 27, 209-220.

Marroig, G., \& Cerqueira, R. (1997). Plio-Pleistocene south American history and the Amazon Lagoon hypothesis: a piece in the puzzle of Amazonian diversification. Journal of Comparative Biology, 2, 103119.

Marshall, L. G. (1985). Geochronology and land-mammal biochronology of the Transamerican fauna interchange. In F. G. Stehli \& S. D. Webb (Eds.), The great American biotic interchange (pp. 49-85). New York: Plenum Press.

Marshall, L. G. (1988). Land mammals and the great American interchange. American Scientist, 76, 380-388.

Marshall, L. G., \& Lundberg, J. G. (1996). Miocene deposits in the Amazonian foreland basin. Science, 273, 123-124.

Marshall, L. G., Butler, R. F., Drake, R. E., Curtis, G. H., \& Tedford, R. H. (1979). Calibration of the great American interchange. Science, 204, 272-279.

Marshall, L. G., Webb, S. D., Sepkoski, J. J., \& Raup, D. M. (1982). Mammalian evolution and the great American interchange. Science, 215, 1351-1357.

Mason, V. C., Li, G., Helgen, K. M., \& Murphy, W. J. (2011). Efficient cross-species capture hybridization and next-generation sequencing of mitochondrial genomes from noninvasively sampled museum specimens. Genome Research, 21, 1695-1704.

Mayr, E. (1963). Animal species and evolution. Cambridge: Harvard University Press.

Mayr, E. (1970). Populations, species and evolution. Cambridge: Harvard University Press.

Miller, M. P. (2005). Alleles in space: computer software for the joint analysis of interindividual spatial and genetic information. Journal of Heredity, 96, 722-724.

Miller, K. G., Kominz, M. A., Browning, J. V., Wright, D. J., Mountain, G. S., et al (2005). The Phanerozoic record of global sea-level change. Science, 310, 1293-1298.

Mittermeier, R. A. (1982). Introduction. International Zoo Yearbook, 22, 1-2.

Mittermeier, R. A., \& Richardson, M. (2013). Conservation of primate populations. Encyclopedia of Biodiversity, 6, 250-260.

Monmonier, M. S. (1973). Maximum-difference barriers: an alternative numerical regionalization method. Geographical Analysis, 5, 245-261.

Moore, W. (1995). Inferring phylogenies from mtDNA variation: mitochondrial-gene trees versus nucleargene trees. Evolution, 49, 718-726.

Morral, N., Bertrantpetit, J., \& Estivill, X. (1994). The origin of the major cystic fibrosis mutation (delta F508) in European populations. Nature Genetics, 7, 169-175.

Nabholz, B., Ellegren, H., \& Wolf, J. B. (2012). High levels of gene expression explain the strong evolutionary constraint of mitochondrial protein-coding genes. Molecular Biology and Evolution, 30, 272-284.

Nei, M. (1987). Molecular evolutionary genetics. New York: Columbia University Press.

Nores, M. (1999). An alternative hypothesis for the origin of Amazonian bird diversity. Journal of Biogeography, 26, 475-485.

Nores, M. (2004). The implications of tertiary and Quaternary Sea level rise events for avian distribution patterns in the lowlands of northern South America. Global Ecology Biogeography, 13, 149-162.

Nylander, J. A. (2004). MrModeltest v2. Program Distributed by the Author. Evolutionary Biology Center, Uppsala University.

Paxton, C. G. M., Crampton, W. G. R., \& Burgess, P. (1996). Miocene deposits in the Amazonian foreland basin. Science, 273, 123.

Pennington, R. T., \& Dick, C. W. (2010). Diversification of the Amazonian flora and its relation to key geological and environmental events: A molecular perspective. In C. Hoorn \& F. Wesselingh (Eds.), Amazonia, landscape and species evolution: A look into the past (pp. 373-385). Oxford: WileyBlackwell. 
Posada, D., \& Buckley, T. R. (2004). Model selection and model averaging in phylogenetics: advantages of akaike information criterion and Bayesian approaches over likelihood ratio tests. Systematic Biology, 53, 793-808.

Posada, D., \& Crandall, K. A. (2001). Intraspecific gene genealogies: Trees grafting into networks. Trends in Ecology \& Evolution, 16, 37-45.

Rambaut, A. (2012). FigTree v1.4. http://tree.bio.ed.ac.uk/software/figtree/.

Rambaut, A., \& Drummond, A. J. (2013a). LogCombiner v1.8.0. http://beast.bio.ed.ac.uk/.

Rambaut, A., \& Drummond, A. J. (2013b). TreeAnnotator v1.8.0. http://beast.bio.ed.ac.uk/.

Rambaut, A., Suchard, M. A., Xie, W., \& Drummond, A. J. (2013). Tracer v1.6. http://tree.bio.ed.ac. $\mathrm{uk} / \mathrm{software} / \mathrm{tracer} /$.

Ramos-Onsins, S. E., \& Rozas, J. (2002). Statistical properties of new neutrality tests against population growth. Molecular Biology and Evolution, 19, 2092-2100.

Rogers, A. R., \& Harpending, H. C. (1992). Population growth makes waves in the distribution of pairwise genetic differences. Molecular Biology and Evolution, 9, 552-569.

Rogers, A. R., Fraley, A. E., Bamshad, M. J., Watkins, W. S., \& Jorde, L. B. (1996). Mitochondrial mismatch analysis is insensitive to the mutational process. Molecular Biology and Evolution, 13, 895-902.

Ruiz-García, M. (1990). Frecuencias alélicas en la población de gatos domésticos de la isla de Menorca (Baleares): Diferentes modelos de Evolución Colonizadora. Evolución Biológica, 4, 307-342.

Ruiz-García, M. (1991). Más sobre genética de poblaciones de Felis catus en la costa Mediterránea Española: Un análisis de la Estructura Genética de las poblaciones naturales de gatos. Evolución Biológica, 5, 227283.

Ruiz-García, M. (1993). Analysis of the evolution and genetic diversity within and between Balearic and Iberian cat populations. Journal of Heredity, 84, 173-180.

Ruiz-García, M. (1994). Genetic profiles from coat genes of natural Balearic cat populations: an eastern Mediterranean and north-African origin. Genetics, Selection, Evolution, 26, 39-64.

Ruiz-García, M. (1997). Genetic relationships among some new cat populations sampled in Europe: a spatial autocorrelation analysis. Journal of Genetics, 76, 1-24.

Ruiz-García, M. (2000). Genetic microstructure in two Spanish cat populations. II: gametic disequilibrium and spatial autocorrelation. Genes \& Genetic Systems, 75, 281-292.

Ruiz-García, M., \& Castillo, M. I. (2016). Genetic structure, spatial patterns and historical demographic evolution of white-throated capuchin (Cebus capucinus, Cebidae, Primates) populations of Colombia and Central America by means of DNA microsatellites. In M. Ruiz-García \& J. Shostell (Eds.), Molecular population genetics, evolutionary biology and biological conservation of the Neotropical primates (pp. 135-172). New York: Nova Science Publishers.

Ruiz-García, M., \& Pinedo-Castro, M. (2010). Molecular systematics and phylogeography of the genus Lagothrix (Atelidae, Primates) by means of mitochondrial COII gene. Folia Primatologica, 81, 109-128.

Ruiz-García, M., \& Pinedo-Castro, M. (2013). Population genetics and phylogeographic analyses of the Jaguarundi (Puma yaguaroundi) by means of three mitochondrial markers: The first molecular population study of this species. In M. Ruiz-García \& J. Shostell (Eds.), Molecular population genetics, evolutionary biology and biological conservation of Neotropical carnivores (pp. 245-288). New York: Nova Science Publishers.

Ruiz-García, M., Castillo, M. I., Vásquez, C., Rodríguez, K., Pinedo, M., et al (2010). Molecular phylogenetics and phylogeography of the white-fronted capuchin (Cebus albifrons; Cebidae, Primates) by means of mtCOII gene sequences. Molecular Phylogenetics and Evolution, 57, 1949-1061.

Ruiz-García, M., Castillo, M. I., Ledezma, A., Pinedo, M., Leguizamon, N., et al (2012). Molecular systematics and phylogeography of Cebus capucinus (Cebidae, Primates) in Colombia and Costa Rica by means of mitochondrial COII gene. American Journal of Primatology, 74, 366-380.

Ruiz-García, M., Vásquez, C., Murillo, A., Pinedo-Castro, M., \& Alvarez, D. (2013a). Population genetics and phylogeography of the largest wild cat in the Americas: an analysis of the jaguar by means of microsatellites and mitochondrial gene sequences. In M. Ruiz-García \& J. Shostell (Eds.), Molecular population genetics, evolutionary biology and biological conservation of Neotropical carnivores (pp. 413-464). New York: Nova Science Publishers.

Ruiz-García, M., Rivas-Sánchez, D., \& Lichilín, N. (2013b). Phylogenetics relationships among four putative taxa of foxes of the Pseudoalopex genus (Canidae, Carnivora) and molecular population genetics of Ps. culpaeus and Ps. sechurae. In M. Ruiz-García \& J. Shostell (Eds.), Molecular population genetics, evolutionary biology and biological conservation of Neotropical carnivores (pp. 97-128). New York: Nova Science Publishers. 
Ruiz-García, M., Pinedo-Castro, M., \& Shostell, J. M. (2014). How many genera and species of woolly monkeys (Atelidae, Platyrrhine, Primates) are? First molecular analysis of Lagothrix flavicauda, an endemic Peruvian primate species. Molecular Phylogenetics and Evolution, 79, 179-198.

Ruiz-García, M., Luengas, K., Leguizamón, N., Thoisy, B., \& Gálvez, H. (2015). Molecular phylogenetics and phylogeography of all the Saimiri species (Cebidae, Primates) inferred from mt COI and COII gene sequences. Primates, 56, 145-161.

Ruiz-García, M., Castillo, M. I., \& Luengas, K. (2016a). It is misleading to use Sapajus (robust capuchins) as a genus? A review of the evolution of the capuchins and suggestions on their systematics. In M. RuizGarcía \& J. Shostell (Eds.), Molecular population genetics, evolutionary biology and biological conservation of the Neotropical primates (pp. 209-268). New York: Nova Science Publishers.

Ruiz-García, M., Castillo, M. I., Luengas, K., \& Leguizamón, N. (2016b). Invalidation of three robust capuchin species (Cebus libidinosus pallidus, C. macrocephalus and C. fatuellus; Cebidae, Primates) in the Western Amazon and Orinoco by analyzing DNA microsatellites. In M. Ruiz-García \& J. Shostell (Eds.), Molecular population genetics, evolutionary biology and biological conservation of the Neotropical primates (pp. 173-208). New York: Nova Science Publishers.

Ruiz-García, M., Luengas-Villamil, K., Pinedo-Castro, M., Leal, L., Bernal-Parra, L. M., \& Shostell, J. M. (2016c). Continuous Miocene, Pliocene and Pleistocene influences on mitochondrial diversification of the capybara (Hydrochoerus hydrochoeris; Hydrochoeridae, Rodentia): incapacity to determine exclusive hypotheses on the origins of the Amazon and Orinoco diversity for this species. Journal of Phylogenetics and Evolutionary Biology, 4, 1-20.

Ruiz-García, M., Vásquez, C., Sandoval, S., Kaston, F., Luengas-Villamil, K., \& Shostell, J. M. (2016d). Phylogeography and spatial structure of the lowland tapir (Tapirus terrestris, Perissodactyla: Tapiridae) in South America. Mitochondrial DNA Part A, 27, 2334-2342.

Ruiz-García, M., Escobar-Armel, P., Thoisy, B., Martínez-Agüero, M., Pinedo-Castro, M., \& Shostell, J. M. (2017). Biodiversity in the Amazon: origin hypotheses, intrinsic capacity of species colonization, and comparative phylogeography of river otters (Lontra longicaudis and Pteronura brasiliensis, Mustelidae, Carnivora) and pink river dolphin (Inia sp, Iniidae, Cetacea). Journal of Mammalian Evolution, 24, 1-28.

Ruiz-García, M., Sánchez-Castillo, S., Ortega, J. M., Castillo, M. I., Luengas, K., Leguizamón, N., Bello, A., \& Shostell, J. M. (2018). The mystery of the genetics origins of Cebus albifrons malitiosus and C. a. hypoleucus: Mitogenomics and microsatellite analyses revealed an amazing evolutionary history of the northern Colombian white-fronted capuchins. Mitochondrial DNA (in press).

Rylands, A. B., \& Mittermeier, R. A. (2013). Familia Cebidae (squirrel monkeys and capuchins). In R. A. Mittermeier, A. B. Rylands, \& D. E. Wilson (Eds.), Handbook of the mammals of the world. 3. Primates (pp. 348-413). Lynx Edicions: Barcelona.

Rylands, A. B., Schneider, H., Mittermeier, R. A., Groves, C. P., \& Rodriguez-Luna, E. (2000). An assessment of the diversity of New World Primates. Neotropical Primates, 8, 61-93.

Rylands, A. B., Mittermeier, R. A., \& Silva, J. S.,. J. (2012). Neotropical primates: taxonomy and recently described species and subspecies. International Zoo Yearbook, 46, 11-24.

Saillard, J., Forster, P., Lynnerup, N., Bandelt, H.-J., \& Norby, S. (2000). mtDNA variation among Greenland Eskimos: the edge of the Beringian expansion. American Journal of Human Genetics, 67, 718-726.

Schneider, H., \& Sampaio, I. (2015). The systematics and evolution of New World Primates: a review. Molecular Phylogenetics and Evolution, 82, 348-357.

Schwarz, G. E. (1978). Estimating the dimension of a model. Annals of Statistics, 6, 461-464.

Smouse, P. E., Long, J. C., \& Sokal, R. R. (1986). Multiple regression and correlation extension of the mantel test of matrix corresponde. Systematic Zoology, 35, 627-632.

Stamatakis, A. (2006). RAxML-VI-HPC: Maximum likelihood-based phylogenetic analyses with thousands of taxa and mixed models. Bioinformatics, 22, 2688-2690.

Tajima, F. (1989). Statistical method for testing the neutral mutation hypothesis by DNA polymorphism. Genetics, 123, 585-595.

Takai, M. (1994). New specimens of Neosaimiri fieldsi from La Venta, Colombia: a middle Miocene ancestor of the living squirrel monkeys. Journal of Human Evolution, 27, 329-360.

Tamura, K., Stecher, G., Peterson, D., Filipski, A., \& Kumar, S. (2013). MEGA6: molecular evolutionary genetics analysis version 6.0. Molecular Biology and Evolution, 30, 2725-2729.

Thalmann, O., Hebler, J., Poinar, H. N., Paabo, S., \& Vigilant, L. (2004). Unreliable mtDNA data due to nuclear insertions: a cautionary tale from analysis of humans and other apes. Molecular Ecology, 13, 321335.

Tirira, D. G. (2016). Mamíferos del Ecuador: Lista actualizada de especies / Mammals of Ecuador: Updated checklist species. Versión 2016.2. Fundación Mamíferos y Conservación. Quito. http://mamiferosdelecuador.com (updated January 30, 2018). 
Tuomisto, H., Ruokolainen, K., \& Salo, J. (1992). Lago Amazonas: fact or fancy? Acta Amazonica, 33, 353361.

Vaidya, G., Lohman, D. J., \& Meier, R. (2011). SequenceMatrix: concatenation software for the fast assembly of multi-gene datasets with character set and codon information. Cladistics, 27, 171-180.

Van der Hammen, T. (1975). The Pleistocene changes of vegetation and climate in tropical South America. Journal of Biogeography, 1, 3-26.

Van der Hammen, T., \& Hooghiemstra, H. (2000). Neogene and quaternary history of vegetation, climate, and plant diversity in Amazonia. Quaternary Science Reviews, 19, 725-742.

Van Roosmalen, M. G. M., \& Van Roosmalen, T. (2013). ORIGIN OF ALLOPATRIC primate species and the principle of metachromic bleaching. Lexington, KY: Amazon.com.

Walsh, P. S., Metzger, D. A., \& Higuchi, R. (1991). Chelex 100 as a medium for simple extraction of DNA for PCR-based typing from forensic material. BioTechniques, 10, 506-513.

Watson, D. F. (1992). Contouring: A guide to the analysis and display of spatial data. New York: Pergamon Press.

Webb, S. D. (1985). Late Cenozoic of mammal dispersals between the Americas. In F. G. Stehli \& S. D. Webb (Eds.), The great American biotic interchange (pp. 357-386). New York: Plenum Press.

Webb, S. D. (1991). Ecogeography and the great American interchange. Paleobiology, 17, 266-280.

Wesselingh, F. P., \& Hoorn, C. (2011). Geological development of Amazon and Orinoco basins. In J. S. Albert \& R. E. Reis (Eds.), Historical biogeography of Neotropical freshwater fishes (pp. 59-67). Berkeley: University of California Press.

Wright, S. (1965). The interpretation of population structure by F-statistics with special regard to systems of mating. Evolution, 19, 395-420.

\section{Affiliations}

\section{Manuel Ruiz-García ${ }^{1} \cdot$ Sebastián Sánchez-Castillo ${ }^{1} \cdot$ María Ignacia Castillo $^{1} \cdot$ Kelly Luengas $^{1} \cdot$ Juan Manuel Ortega ${ }^{1} \cdot$ Pablo Moreno $^{2} \cdot$ Luis Albuja $^{3} \cdot$ Christian Miguel Pinto $^{3} \cdot$ Joseph Mark Shostell ${ }^{4}$}

\section{Manuel Ruiz-García}

mruizgar@yahoo.es; mruiz@javeriana.edu.co

1 Laboratorio de Genética de Poblaciones Molecular-Biología Evolutiva, Unidad de Genética Departamento de Biología, Facultad de Ciencias, Pontificia Universidad Javeriana, Bogotá, DC 110231, Colombia

2 Instituto Nacional de Biodiversidad, Quito 170135, Ecuador

3 Instituto de Ciencias Biológicas, Escuela Politécnica Nacional, Quito 17012759, Ecuador

4 Math, Science and Technology Department, University of Minnesota Crookston, Crookston, MN 56716, USA 